\title{
Analysis of syngas methanation for bio-SNG production from wastes: kinetic model development and pilot scale validation
}

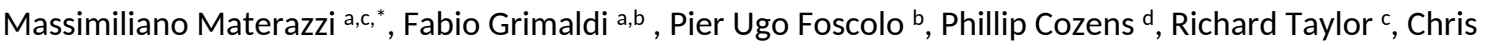 \\ Chapman ${ }^{\mathrm{c}}$
}

\begin{abstract}
a Department of Chemical Engineering, University College London; Torrington Place, London WC1E 7JE, UK
${ }^{b}$ Dipartimento di Ingegneria industriale, Universita' di L'Aquila, Monteluco di Roio, 67040 L'Aquila, Italy

${ }^{c}$ Advanced Plasma Power Ltd, South Marston Business Park, Swindon SN3 4DE, UK

d Progressive Energy Ltd, Swan House, Bonds Mill, Stonehouse, GL10 3RF, UK
\end{abstract}

\section{Abstract}

Bio-substitute natural gas (or bio-SNG) produced from gasification of waste fuels and subsequent methanation of the product gas could play a crucial role in the decarbonisation of heating and transportation, and could be a vital part of the energy mix in the coming decades. Although the methanation of trace quantities of carbon oxides has been practiced commercially for many years, methanation from syngas poses a more severe problem due to the high and unstable concentrations of reactants in the produced gas. In this work, a low-Ni methanation catalyst was tested in a differential reactor to derive a kinetic model that could determine a practical operating scheme for the first methanation step of a typical bio-SNG process. The model, comprising water gas shift and methanation reactions, along with their reverse reactions, was used for realistic modelling of the methanation process using high quality syngas, obtained from steam-oxygen gasification of wastes and gas plasma conversion, and to better determine the operation conditions in the first reactor of a bio-SNG pilot plant in Swindon (UK). The tests undertaken show that the catalyst was performing as expected using the waste-derived syngas at industrially relevant conditions, when compared to predictions of models derived from works using bottled gases. This gives confidence that the same approach can be used for the detailed design and operation of once through methanation reactor elements and process system configuration for bio-SNG production at larger scale.

\section{Nomenclature}

\begin{tabular}{|c|l|l|}
\hline$\Delta \mathrm{H}_{\mathrm{R}}^{0}$ & Standard enthalpy of reaction & $\mathrm{kJ} \mathrm{mol}^{-1}$ \\
\hline$G H S V$ & Gas hourly space velocity & $\mathrm{h}^{-1}$ \\
\hline$F_{i}$ & Molar flowrate of $\mathrm{i}^{\text {th }}$ component & $\mathrm{mol} \mathrm{h}^{-1}$ \\
\hline$y_{i}$ & Molar (or volume) fraction of $\mathrm{i}^{\text {th }}$ component & - \\
\hline$v$ & Volumetric flowrate & $\mathrm{ml} \mathrm{h}^{-1}$ \\
\hline$V_{c a t}$ & Volume of catalyst & $\mathrm{cm}^{3}$ \\
\hline$r_{C H 4}$ & Methane formation rate (molar) & $\mathrm{mol} \mathrm{cm}^{-3} \mathrm{~h}^{-1}$ \\
\hline$r_{C H 4}^{\prime}$ & Methane formation rate (volumetric) & $\mathrm{mol} \mathrm{cm}^{-3} \mathrm{~h}^{-1}$ \\
\hline$X_{C O}$ & CO conversion (\%) & $\mathrm{vol}^{\prime} \%$ \\
\hline$k$ & Kinetic constant & $\mathrm{mol} \mathrm{h}^{-1} \mathrm{~cm}^{-3} \mathrm{bar}^{-\mathrm{n}}$ \\
\hline$E a$ & Apparent activation energy & $\mathrm{kJ} \mathrm{mol}^{-1}$ \\
\hline$A$ & Pre-exponential factor & $\mathrm{mol} \mathrm{h}^{-1} \mathrm{~cm}^{-3} \mathrm{bar}^{-\mathrm{n}}$ \\
\hline$P_{i}$ & Partial pressure of ith component $\left(P * y_{i}\right)$ & $\mathrm{bar}^{\prime}$ \\
\hline
\end{tabular}




\begin{tabular}{|c|c|c|c|}
\hline$D_{e f f}$ & \multicolumn{2}{|c|}{ Effective diffusivity for $\mathrm{CO}$ in pellet } & $\mathrm{cm}^{2} \mathrm{~s}^{-1}$ \\
\hline$d$ & \multicolumn{2}{|c|}{ Particle diameter } & $\mathrm{cm}$ \\
\hline$R$ & \multicolumn{2}{|l|}{ Gas constant } & $\mathrm{cm}^{3}$ bar $\mathrm{K}^{-1} \mathrm{~mol}^{-1}$ \\
\hline$T$ & \multicolumn{2}{|l|}{ Temperature } & $\mathrm{K}$ \\
\hline$P$ & \multicolumn{2}{|l|}{ Pressure } & bar \\
\hline$\Delta$ & \multicolumn{2}{|l|}{ Outlet - Inlet } & - \\
\hline alpha & \multicolumn{2}{|c|}{ Methanation reaction order for $\mathrm{H}_{2}$} & - \\
\hline beta & \multicolumn{2}{|c|}{ Methanation reaction order for $\mathrm{CO}$} & - \\
\hline$n$ & Methanation reaction ordel & lpha+beta) & - \\
\hline \multicolumn{2}{|c|}{ Abbreviations } & \multicolumn{2}{|l|}{ Subscripts } \\
\hline SNG & Substitute natural gas & in & reactor inlet \\
\hline GHG & Greenhouse gases & out & reactor outlet \\
\hline CNG & Compressed natural gas & $i$ & ith gas species \\
\hline PSA & Pressure swing adsorption & $c$ & catalyst \\
\hline RDF & Refuse derived fuel & & \\
\hline WGS & Water gas shift & & \\
\hline rWGS & Reverse water gas shift & & \\
\hline SMR & Steam methane reforming & & \\
\hline FTIR & Fourier transform infrared & & \\
\hline MSW & Municipal solid waste & & \\
\hline GCV & Gross calorific value & & \\
\hline NCV & Net calorific value & & \\
\hline
\end{tabular}

\section{Introduction}

Because of the increasing demand for natural gas and the need for reduction of greenhouse gases (GHG) emissions, in the last three decades interests have focused on the production of bio substitute natural gas (bio-SNG), which has been suggested as an important future energy carrier. Recent studies have demonstrated that large quantities of grid-injected renewable gas will be required in the coming decades to replace a proportion of fossil gas supplies, in order to meet GHG reduction targets whilst continuing to use gas for heating [1]-[4]. Similarly, for transportation, with the bioSNG delivered by the gas grid to customers and then made into CNG (compressed natural gas) for use as a road fuel, the cost per tonne of $\mathrm{CO}_{2}$ abated appears to be significantly lower than the cost for electric vehicles and is a credible option for trucks where the electric option is not practical [5]. A proportion of this renewable gas could be derived from wet wastes via anaerobic digestion, but insufficient bio-resources are available from this source alone to provide all the renewable gas that will be required. Therefore, it is necessary to develop an alternative pathway to manufacture renewable gas from biogenic waste resources via advanced thermal processes.

The conventional thermal route for SNG (substitute natural gas) production is based on the gasification of coal or biomass to synthetic gas (syngas) [6]. After gas cleaning and conditioning, the syngas containing $\mathrm{H}_{2}, \mathrm{CO}, \mathrm{CO}_{2}$, and $\mathrm{H}_{2} \mathrm{O}$ can be converted to SNG by catalytic hydrogenation of carbon oxides (mainly $\mathrm{CO}$ ), otherwise known as methanation. Although the methanation of trace quantities of $\mathrm{CO}$ (and to a minor extent, $\mathrm{CO}_{2}$ ) has been practiced commercially for many years in hydrogen upgrading for ammonia plants and fuel cell applications [7]-[9], methanation from syngas poses a more severe problem due to the high concentrations and variability of reactants in the produced gas [10]. 
The possibility to raise high pressure steam and to generate thereby important economic synergies, favored the application of adiabatic fixed bed reactors for large scale coal to SNG plants [11], [12]. Series of adiabatic fixed bed methanation reactors were used in the first large scale coal to SNG plant (Great Plains, North Dakota, in operation since 1984) and intended for a number of coal to SNG projects in the United States in the first decade of the 21st century [12]. In the last 25 years, the use of biomass as feedstock has also been increasingly investigated, especially in Europe with the GoBiGas project for the production of bio-SNG from wood [13]. However, biomass to SNG plants are significantly smaller than coal to SNG plants due to lower feedstock availability [11]. At this scale (10-100 MW), the advanced gas cleaning technologies needed to make syngas suitable for chemical conversion are no longer cost effective. For example, a high number of thiophenic species (thiophene, benzo-thiophene and dibenzo-thiophene and their derivatives), unsaturated hydrocarbons (e.g. ethylene, acetylene, etc.) and light aromatics are largely present in the producer gas from gasifiers and are known to be harmful to methanation catalysts [14]. In large scale coal-to-SNG plants, these species are removed reliably by the Rectisol ${ }^{\circledR}$ scrubbing leading to low hydrocarbons and total sulphur content below $100 \mathrm{ppb}$ [15], [16]. In small and medium scale biomass-to-SNG plants however, economics would not allow the application of such low temperature/high pressure physical washing units, and combination of chemical reactors (so-called olefin hydrogenation) followed by an amine scrubber (where most of the $\mathrm{H}_{2} \mathrm{~S}$ and $\mathrm{CO}_{2}$ are sequestered before the catalytic stages) have to be used [12]. Furthermore, the importance to generate steam at the highest pressure level is reduced due to completely different energy integration options [3]. All these issues are particularly exacerbated when operating on waste materials (municipal solid waste, commercial and industrial wastes, etc.), due to the unfavourable and inconsistent characteristics of the feedstock [17]. Conventional gasification and bio-SNG systems have characteristics which make them inherently unstable when operating on wastes, and achieving high levels of availability required with a heterogeneous waste derived fuel is technically difficult [18]. As a result, combinations of new gasification technologies and methanation steps are being developed in parallel.

To date, thermal gasification of virgin wood to biogenic natural gas, or bio-SNG has been demonstrated at small scale, and a commercial scale production facility will be operating in Europe [13] for the treatment of forest residues, but the manufacture of bio-SNG from urban wastes has not yet been demonstrated. The future success of technologies for producing bio-SNG from waste materials is equally determined by the gasifier design, feedstock nature and process conditions in both gasification and methanation steps. Fluid bed systems are currently the most employed in waste and biomass gasification for their ability to handle different materials. They include a range of different designs, such as bubbling fluid bed (BFB), circulated fluid bed (CFB) and dual fluid bed [19]. The expanded bed of inert particles creates a large mass of hot material that is able to absorb and mitigate fluctuations in fuel conditions with little-to-no change in performance [20]. However, with high volatility (more than $60 \%$ ) and low ignition temperature $\left(250-350{ }^{\circ} \mathrm{C}\right.$ ), waste material is prone to devolatise immediately after the injection into the reactor, making it more susceptible to tar formation and sulphur contaminants release when compared to other fuels, such as biomass or coal [21]. Furthermore, the significant quantity of fly ash in waste materials is such that high dust loading is expected in the producer gas which the downstream units must be able to accommodate [22]. These considerations led to the development of different reactors configuration. One possible approach involves the combination of a primary waste treatment unit (e.g. bubbling fluidised bed) 
and a high temperature refining stage, such as an ash melting furnace or a plasma converter. The high temperature in the second stage can be used to break down tar and thiophenes enhancing the quality of the syngas remarkably, and to vitrify the ashes generated from the first stage, which would otherwise pose both operational and disposal problems as occurs for most other thermochemical waste conversion processes [17], [18], [23].

The other important factor to be considered is the design and operation of the methanation step. Besides the reactor configuration concepts, catalysts are crucial as they influence not only the activity and the selectivity of the reactions, but also the up-and downstream processes [12].

The most common catalysts typically used in the methanation process are nickel metal dispersed on a support material consisting of various oxide mixtures such as alumina, silica, lime, magnesia and compounds such as calcium aluminate cements [7], [24], [25]. Along with the high sensitivity to sulphur and other contaminants, nickel catalysts cause relatively high reaction rates and consequently very high heat fluxes are also generated [26]. The complex and variable composition of the waste-derived syngas leads to variety of possible reactions occurring on the surface of the methanation catalyst that could affect the methane yield, or also result in undesired by-products (see Table 1). For example, carbon oxides and unsaturated hydrocarbons (e.g. $\mathrm{C}_{2} \mathrm{H}_{4}, \mathrm{C}_{2} \mathrm{H}_{2}$ ) can be decomposed into different types of surface carbon that either might be hydrogenated to methane or form carbonaceous deposits [27]. Although the nickel crystallite stays active for methanation and other reactions, the growth of these carbon fibres (or whiskers) will lead to blockage of pores and can destroy the catalyst particles mechanically, such that blockage of the complete reactor tube can be caused within hours or days [28]. Furthermore, due to the additional key requirement for the product gas to have a low level of inerts, such as nitrogen and argon, thermal control of reaction in undiluted gas mix becomes a serious issue [12].

Problems connected with poisoning, localized coking and catalyst sintering generally lead to complex reactor designs which are not always suitable for successful operation on waste feedstock. The current approach is to focus primarily on an enhancement of temperature control, cost efficiency and process flexibility due to the fluctuating availability and composition of waste derived syngas [12], [29]. The recycling of product gas containing water and $\mathrm{CH}_{4}$ is often used in the adiabatic fixedbed methanation process in order to cut down reaction heat. For an example, in TREMPTM technology developed by Haldor Topsøe (Denmark), product gas recycle is used to control the temperature in the first methanation reactor (which is usually the most problematic) with a feed ratio of $\left(\mathrm{H}_{2}-\mathrm{CO}_{2}\right) /\left(\mathrm{CO}+\mathrm{CO}_{2}\right)=3$ [29]. However, this adds significant costs in term of reactor volumes and compressing duties, and additional operations like $\mathrm{CO}_{2}$ removal before methanation are often required to offset the larger volumes needed. To avoid gas recycling and internal reactor cooling, steam addition, firstly introduced by Imperial Chemical Industries (ICI) in the 1970s, and then applied by Amec Foster Wheeler and Clariant in their VESTA process, is also a valuable option [30]. However, process conditions should be controlled so that the concurrent water gas shift (WGS - R2) and methane reforming (R4) reactions do not penalise the methane yield [31], [32]. Given the large variability of the syngas composition in the methanation stage and the number of reactions involved therein, a detailed understanding of the thermodynamics and kinetics of the involved reactions is necessary to properly design and optimize such reactors and, more importantly, to limit the risks during up-scaling from laboratory over pilot to commercial scale. Almost all the studies in the literature on $\mathrm{CO}$ methanation deal mostly with integral reaction conditions or separately 
concentrate on either $\mathrm{CO}$ or $\mathrm{CO}_{2}$ methanation, without considering other side reactions (i.e. water gas shift) [33], [34]. There are few publications investigating all reactions at the same time under differential reaction conditions, which are certainly needed to draw conclusions on the reaction behaviours under realistic industrial conditions and on the ways to optimize methane production over other by-products [35]-[37]. Simulation models most frequently apply the LangmuirHinshelwood (LH) kinetics published by Wu and Froment [35] and Kopyscinski [11]. However, the validity of these kinetic models is limited and depends on the applied catalyst and reaction conditions. Especially for the dynamic simulation of methanation processes with wide temperature and concentration ranges, reactions rates could be best described by means of one or more kinetic power law equations. Compared to the LH based rate expression (which is derived from a postulated reaction mechanism), a power law expression is often used as a relatively simple approximation, for fitting experimental data where a certain range of conditions are tested.

The objective of this work is to prove the feasibility of bio-SNG production in steady-state operation of a pilot plant processing municipal solid waste (MSW) using a two-stage fluid bed-plasma system. Firstly, a low-Ni methanation catalyst was tested in laboratory conditions to derive an empirical power law based kinetic model that could determine a practical reactor operating scheme for the first methanation reactor. The model results were then validated on high quality syngas, obtained by steam-oxygen gasification of waste residues followed by plasma conversion, in the Swindon (UK) pilot plant, which was designed to demonstrate the technical potential of producing a pipeline quality bio-SNG from MSW. The main conversion blocks and plant scheme are also presented, along with preliminary results on the reactors operation on waste feedstock. The synergetic use of modelling along with the experimental work with real syngas from wastes will help improving and accelerate the reactor and process development and limit the risks during scale-up.

\section{Experimental}

\subsection{Apparatus}

The experimental set-up used in this study is shown in Figure 1. The rig was fitted with pre-blended bottled gas supplies. Each of the gas cylinders was fitted with a needle valve controller while the $\mathrm{N}_{2}$ flow was controlled by a mass flow controller. The inlet temperature at the reactor was controlled by the amount of pre-heat given to the reagents by the electrical furnace. The reactor is a tube (1.2" OD x 32" long; 0 - 40 bar. Central 1/4" thermowell containing 4 thermocouples with 1 separate outlet thermocouple) packed with the solid catalyst, the entirety of which was lagged with a high temperature resistant material, coupled with Rockwool and an outer metal sheath.

The upstream end of the reactor tube was packed with inert alumina beads. The active catalyst bed was positioned towards the exhaust end of the reactor. The catalyst used for the series of test runs was a commercial methanation catalyst supplied in pellet form by Catal International Ltd (Table 2). In the experiments, crushed material with particle diameters between 0.15 and $0.80 \mathrm{~mm}$ were used to avoid any intrusive effects by pore diffusion. The catalyst was used in a $50 \%$ diluted form, with inert alumina $2 \mathrm{~mm}$ spheres used as diluent. The actual volume of catalyst was given by the preliminary tests on spatial velocity (see next section). As an initial test, an indicative path length of $22 \mathrm{~mm}$ was considered. 
The reacting fluid moves through the reactor tube in turbulent flow to ensure the absence of temperature, velocity and concentration gradients in the radial direction. The entire reactor tube was externally heated within a muffle furnace arrangement. The cooling line tees off the product line at the bottom of the reactor and near its exit end, a pressure indicator and control valve (PIC) are connected. Upon condensation of steam, the exhaust line was routed to an atmospheric vent, with a gas sample line taken from a sample point close to the steam condenser. Gas composition was analyzed by gas chromatography (GC, PerkinElmer, Auto System XL chromatography).

The catalyst bed dimensions and particle characterization are indicated in Table 2 below:

\subsection{Operational procedure}

For each of the main experimental runs, the reactor was initially heated utilising an externally heated muffle furnace, to a temperature in excess of $300^{\circ} \mathrm{C}$ for catalyst reduction using hydrogen as the reducing agent. During this period nitrogen was used as an inert gas carrier. Subsequently, the fresh catalyst was tested under reactive conditions until a constant activity was reached (Figure 2). Initially, the sudden increase in temperature leads to the reaction proceeding with a significant heat release within the catalytic cell. This "exceptionally high" initial activity is typical of fresh catalyst, and is attributable to chemical interaction of active sites with carbon oxides resulting in formation of carbon containing surface groups until saturation [35], [38]; after the break-through point (dashed line), the conversion decreases characterizing the "steady-state" region whereon this study is focused. The system is then cooled down to below $330^{\circ} \mathrm{C}$ with purge nitrogen, and the temperature normalised to the set-point value.

The experimental procedures aim to establish near isothermal conditions for the methanation reaction by limiting the path length of the catalyst bed, which together with a low residence time, and a sufficiently dilute feedstock, will give a small but detectable temperature rise in the process stream. This was repeated for a number of temperature intervals for the incoming feedstock between approx. 320 and $550{ }^{\circ} \mathrm{C}$. From previous experiments, a minimum space velocity was selected for proposed catalysts/reactor configuration (i.e. 18,000h-1) which was well in excess of the diffusion limit threshold. This was to avoid the requirement to experimentally establish the diffusion limit for the system [35].

To determine the kinetic equation for syngas methanation, using a specified gas feed, a series of extended catalyst test runs were carried out on the catalyst system using the previously established reactor set up and operating procedures. Within a series of $12 \mathrm{x} \sim 8 \mathrm{hr}$ test runs, the activity of the catalyst and product gas analysis was studied. The most significant test run data is summarised in the table of run conditions -Table 3:

A number of runs with high $\mathrm{CO}_{2}$ content (Runs 11 and 12) were also performed to assess the effect of $\mathrm{CO}_{2}$ in the syngas. This is particularly relevant to waste applications, where $\mathrm{CO}_{2}$ content from the gasifier can be as high as $20-30 \%$ in volume in syngas before the water gas shift reactor (see Section 4.1), and up to $40-50 \%$ after [21]. The total reaction pressure was maintained at 1 bar in all runs. Although higher pressure leads to higher CO conversion, it also accelerates catalyst deactivation, as reported by [37], and so was not considered at this project stage. 
The generic steady-state mole balance over a small section of the tubular catalytic reactor $d V_{\text {cat }}$ (modelled as a plug flow kinetic system) is given as the following for methane:

$$
0=F_{C H 4, \text { in }}-\left(F_{C H 4, i n}+d F_{C H 4}\right)+r_{C H 4} d V_{c a t}
$$

or

$$
r_{C H 4}=\frac{d F_{C H 4}}{d V_{c a t}} \quad\left[\mathrm{~mol} / \mathrm{cm}_{\text {cat }}^{3} \mathrm{~h}\right]
$$

where $F_{C H 4}$ is the molar flow rate of methane, and $r_{\mathrm{CH} 4}$ represents the rate of formation of methane per unit volume of catalyst. Since any change in flowrates of reactants is very small and the temperature rise is limited, it is reasonable to assume the overall volumetric flowrate to be constant. Thus, Eq. 2 can be written as

$$
r_{C H 4}^{\prime}=\frac{R T}{P} \frac{d F_{C H 4}}{d V_{c a t}}=v \frac{d y_{C H 4}}{d V_{c a t}} \quad\left[\mathrm{ml} / \mathrm{cm}_{\text {cat }}^{3} h\right]
$$

where $y_{C H 4}$ is the molar fraction of methane at the outlet and $v$ the total volumetric flowrate (expressed in millilitres per hour, $\mathrm{ml} \mathrm{h}^{-1}$ ). The proposed approach assumes the rate to be constant throughout the catalyst bed and interprets it as the rate corresponding to the methane composition measured at the outlet, which is a reasonable approximation for high dilutions and quasi-isothermal conditions. By defining the gas hourly space velocity (GHSV) as the ratio between the volumetric flowrate $(v)$ and the entire catalyst volume $\left(V_{c a t}\right)$, it follows that the rate of methane formation $r_{\mathrm{CH} 4}$ can be obtained directly from:

$$
r_{C H 4}^{\prime}=y_{C H 4} * G H S V \quad\left[m l / m_{c a t}^{3} h\right]
$$

which comes from integration of Eq. 3 over the entire catalyst cartridge. Analogously, the expression for the reaction rate for a generic $\mathrm{i}$-component is:

$$
r_{i}^{\prime}=\Delta y_{i}^{*} G H S V
$$

where $\Delta y_{i}$ is the difference in molar fraction of the i-component between inlet and outlet of the reactor.

Considering the CO methanation and WGS as the only reactions occurring in the examined temperature range it follows that:

$$
\begin{gathered}
r_{C H 4}^{\prime}=\Delta y_{C H 4}{ }^{*} G H S V \\
r_{C O 2}^{\prime}=\Delta y_{C O 2}{ }^{*} G H S V \\
r_{C O}^{\prime}=-r_{C H 4}^{\prime}-r_{C O 2}^{\prime}=\Delta y_{C O}{ }^{*} G H S V \\
r_{H 2}^{\prime}=-3 r_{C H 4}^{\prime}+r_{C O 2}^{\prime}=\Delta y_{H 2}{ }^{*} G H S V
\end{gathered}
$$

CO conversion (at constant temperature): 


$$
X_{C O}(\%)=\frac{v_{C O, \text { in }}-v_{C O, \text { out }}}{v_{C O, \text { in }}} * 100
$$

Figure 3 shows the temperature dependent conversions of $\mathrm{CO}$ on the $8 \% \mathrm{Ni} / \mathrm{Al}_{2} \mathrm{O}_{3}$. The two curves depict the conversion during the methanation reaction in $\mathrm{CO}_{2}$-free (Run 6) and $\mathrm{CO}_{2}$-rich (Run 11) gas mixtures. In both cases, the $\mathrm{CO}$ conversion results in a typical hump-shaped curve, starting at $360^{\circ} \mathrm{C}$ with a very low conversion $(<5 \%)$, and peaking at $460{ }^{\circ} \mathrm{C}$ with the highest value $(\sim 80 \%)$. The agreement between conversion of $\mathrm{CO}$ alone and with $\mathrm{CO}_{2}$ suggests that both $\mathrm{CO}_{2}$ and water formed by conversion of $\mathrm{CO}$ do not affect significantly the methanation reaction, at least at low-medium temperatures. The decrease in conversion for higher temperatures in both cases indicates the occurrence of the reverse reaction, also known as steam reforming, which converts the produced methane back to carbon monoxide. In the $\mathrm{CO}_{2}$-rich case, the effect is more pronounced due to the reverse water gas shift which also increases carbon monoxide. It is therefore important to include all these additional pathways into the model, in order to get a reliable description of the process across a wide temperature range.

\section{Model development}

The kinetic data sought included both the activation energy for the methanation reaction (R1), and the order of the reaction with respect to $\mathrm{H}_{2}$ and $\mathrm{CO}$ concentration. Steam methane reforming (R4), water gas shift (R2) and reverse water gas shift (R5) reactions, all of which took place simultaneously with $\mathrm{CO}$ methanation in the reactor, where also analysed in the same trials.

\subsection{Methanation reaction orders for $\mathrm{CO}$ and $\mathrm{H}_{2}$}

The selected rate data where CO methanation was the dominant reaction (Runs 1-10, low temperature range, i.e. $\mathrm{T}<470^{\circ} \mathrm{C}$ ) were analysed and fitted to an empirical power law model of the form:

$$
\begin{gathered}
r_{C H 4}^{\prime}=k * p_{C O}^{a l p h a} * p_{H 2}^{b e t a} \\
k=A * e^{\left(-\frac{E a}{R T}\right)}
\end{gathered}
$$

Where $k$ is the kinetic constant of the reaction, $A$ is the pre-exponential factor and $E a$ the apparent activation energy. The influence of the reactant concentration on the methanation reaction was investigated by determining the reaction orders for $\mathrm{CO}$ and $\mathrm{H}_{2}$, alpha and beta. This was done by stepwise varying the $\mathrm{CO}$ partial pressure from 0.011 to 0.061 bar and $\mathrm{H}_{2}$ from 0.258 to 0.72 bar, while keeping that of the second reactant constant, and going back again to the initial partial pressure. The same tests were repeated several times across different temperatures (see Table 3, Runs 1-10). Equation (6) was then rearranged to calculate the reaction orders alpha and beta from the experimental rate measurements at each condition described above. This could be done by taking the logarithm of both sides, and rearranging Equation (6) in the form $y=m x+b$. When plotted, the value of the slope of each line would give the reaction order at each specific condition, as: 


$$
\text { alpha }=\left(\frac{\partial \ln r_{C H 4}^{\prime}}{\partial \ln P_{C O}}\right)_{T, P_{H 2}}, \quad \text { beta }=\left(\frac{\partial \ln r_{C H 4}^{\prime}}{\partial \ln P_{H 2}}\right)_{T, P_{C O}}
$$

The plots for derivation of alpha and beta at varying temperature and carbon monoxide/hydrogen concentrations are shown in Figure 4 (partial pressures are reported in $\mathrm{kPa}$ to show positive values when changing scale from linear to logarithmic).

It can be seen that all plots are linear, confirming that the empirical power rate law is suitable for modelling the kinetics of methanation over the chosen catalyst using selected gas compositions and temperature range. The order in CO partial pressure, for example, ranges between -0.16 and +0.1 , increasing with temperature over the examined operating conditions. Conversely, the order in $\mathrm{H}_{2}$ ranged from 0.66 to 0.4 and decreased with temperature (see Figure 5).

These trends prove to be in very good agreement with findings of Van Meerten and al. (1982), who studied the kinetics of the methanation of carbon monoxide on a low nickel catalyst at atmospheric pressure in a differential flow micro-reactor[39]. In his study, the methanation of $\mathrm{CO}$ was measured over a much wider range of experimental conditions; the temperature was varied from $130{ }^{\circ} \mathrm{C}$ up to $570{ }^{\circ} \mathrm{C}$, the partial pressure of carbon monoxide from 0.001 bar to 0.855 bar and the partial pressure of hydrogen from 0.072 bar to 0.921 bar. As in this case, the main findings were that the reaction order with respect to $\mathrm{H}_{2}$ and $\mathrm{CO}$ was a linear function of temperature (Figure 6). In addition, both reactants were found to have an influence on the order of reaction of the other, suggesting a competitive adsorption of $\mathrm{H}_{2}$ and $\mathrm{CO}$ on the active sites. In order to demonstrate further the remarkable consistency of our data, we compared the plots of Figure 5 with those of Figure 6, which are based on a selected range of partial pressures typical of real plant operation. These have been extracted from the very extensive experimental conditions explored by van Meerten in his early work [39]. A parametric equation for determining reaction orders at different conditions was derived from Figure 6, by using simple linear regression with a spreadsheet, with the final reactants order equations given in Table 4.

For constant $\mathrm{CO}$ and $\mathrm{H}_{2}$ partial pressures ( 0.06 and 0.25 bar, respectively), Equations 9 and 10 reduce to alpha $=0.0017^{*} T-0.59$ and beta $=-0.0015^{*} T+1.16$, which fit our data surprisingly well (Figure 5). This gives reasonable confidence that empirical Equations 9 and 10 could form a suitable basis for modelling $\mathrm{CO}$ methanation under the wide range of reaction conditions that could be expected in waste to gas operations.

\subsection{Kinetic constant and temperature dependence}

The apparent activation energy $\left(E a^{\prime}\right)$ was derived from the Arrhenius equation (7), rearranged as:

$$
E a^{\prime}=-R *\left(\frac{\partial \ln k}{\partial\left(\frac{1}{T}\right)}\right)_{P_{H 2}, P_{C O}}
$$

Due to variability of reactions orders at different partial pressures of reactants, also in this case the different partial pressure combinations produce different lines in the Arrhenius plot, of the same general trend as shown in Figure 7. However, the difference between data points at specific 
temperatures proved to be not significantly high and tended to decrease as temperature goes below $400{ }^{\circ} \mathrm{C}$, where values of $\mathrm{Ea}$ ranged from 90 to $105 \mathrm{~kJ} \mathrm{~mol}^{-1}$.

The relevant kinetic data for the reverse reaction (i.e. methane steam reforming) on the same catalysts were further investigated by analysing the data points of the same runs at high temperatures $\left(>460{ }^{\circ} \mathrm{C}\right.$ ). Arrhenius plots provide the apparent activation energies for methane steam reforming (Figure 8). The apparent activation energies for the overall methane reduction between 450 and $530{ }^{\circ} \mathrm{C}$ on the Ni catalysts were estimated from the slopes, giving $193.5 \mathrm{~kJ} \mathrm{~mol}^{-1}$.

From a preliminary analysis of the data points available, the steam reforming reaction was initially assumed to be of first order with respect to methane and independent from steam concentration, as also confirmed by other studies [40], [41]. By minimizing the sum of squares of the deviations between the measured and the computed values, a better value of the order of reaction was then determined (i.e. 0.92). Finally, data points where $\mathrm{CO}$ and $\mathrm{CO}_{2}$ varied independently from methane formation/reforming were considered separately, and attributed to direct and reverse water gas shift reactions [35], [36]. The WGS reactants orders and apparent activation energy could be derived from the runs where $\mathrm{CO}_{2}$ production was evident. WGS Ea was found to be fairly consistent across different runs, ranging from $57.1 \mathrm{~kJ} \mathrm{~mol}^{-1}$ to $59.9 \mathrm{~kJ} \mathrm{~mol}^{-1}$ as shown in the Arrhenius plot of Figure 9 (left). Analogously, the reverse shift reaction was introduced by assuming that the consumption of carbon dioxide is equal to the difference between the predicted rate of the power law equation for WGS, and the experimental rate in the different experimental conditions. The regression led to values of Ea of 151.3-180.0 kJ mol-1, which are in line with those reported in the literature [35].

The completion of the above procedure for the 4 reactions considered in this study allowed a model for the reaction network to be produced, and is summarised in Table 5. It is interesting to note that the combination of reverse water gas shift and $\mathrm{CO}$ methanation determines the production of methane from $\mathrm{CO}_{2}$. This is also known as Sabatier reaction ( $\mathrm{R} 3$ in Table 1), and reported to occur on $\mathrm{Ni}$ catalysts when CO concentration is particularly low (<2\%) [42]-[44].

\subsection{Comparison with theoretical models}

The literature reports other models based on postulated mechanisms derived using a LangmuirHinshelwood approach, assuming one rate determining step with all other elementary steps in equilibrium [35], [39], [45], [46]. In the present work, two of these models are presented in Table 6 and employed for comparison with our developed model. One is the $\mathrm{Xu}$ and Froment model, developed for steam methane reforming and water gas shift on $\mathrm{Ni}$ catalyst with temperatures above $500^{\circ} \mathrm{C}$ [35]. The second model for comparison is the one proposed by van Meerten, chosen for the equivalence of reaction order parameters already noted in previous section [39]. The latter, however, does not include other side reactions, and can only be applied with the assumption that CO methanation is the dominant reaction.

The kinetic equations were subsequently implemented into the RPlug reactor in the Aspen Plus software for comparison with experimental data (Figure 10). Thermal mode of reactor was set as 
isothermal, with temperature varying from $370^{\circ} \mathrm{C}$ to $520^{\circ} \mathrm{C}$ to better replicate the conditions of the reactor in the laboratory rig.

For low to medium temperatures (up to $\sim 430{ }^{\circ} \mathrm{C}$ ), both alternative models provide a good agreement with experimental and power law model results, with a better fitting given by van Meerten equation. The similarity of these two additional models is that the rate limiting steps are assigned in both cases to dissociative absorption of $\mathrm{CO}$ and addition of a hydrogen atom to adsorbed $\mathrm{CH}$ [39]. Beyond $430{ }^{\circ} \mathrm{C}$, the two models start diverging significantly, with Xu \& Froment model describing more closely what would be predicted by the power law and shown by experimental data. In this sense, the concurrence of water gas shift and reverse reaction at higher temperatures, which could not be predicted by van Meerten, seems to affect significantly the overall CO conversion. Noteworthy, the reverse water gas shift could be particularly important in the presence of larger fractions of $\mathrm{CO}_{2}$, typical of waste derived syngas applications.

Although lacking of a mechanistic fundament, combined power-law rate equations were giving the best fit to experimental data. It should be noted, however, that proposed rates can only give accurate predictions within the experimental boundaries examined in this and van Meerten's work (i.e. operating temperature: $310-580^{\circ} \mathrm{C}$, range of partial pressures: $\mathrm{P}_{\mathrm{CO}}=0.026-0.86$ bar, $\mathrm{P}_{\mathrm{H} 2}=0.132-$ 0.921 bar, $\mathrm{P}_{\mathrm{CO} 2}=0.0-0.411$ bar).

\section{Pilot plant validation}

In this section, the new-developed model has been used to generate projections of the initial methanation behaviour at a different scale. In order to avoid excessive boundary layer effects and provide realistic fluid, mechanical and thermal behaviour of the products in a commercial bio-SNG plant, experimental tests were performed in a moderately large scale bio-SNG pilot plant, using syngas derived from waste materials. Without this work, the methanation performance projections would be just extrapolations from small lab-scale apparatus, subject to major uncertainty associated with the usage of unvalidated models.

\subsection{Plant description}

The syngas used in this study is a waste-derived syngas from Advanced Plasma Power's (APP) existing Gasplasma pilot facility, located at Swindon (UK), which is then converted and upgraded in a new, dedicated conversion and clean up plant (Figure 11). The front-end plant for syngas generation and its operation are described in details in Materazzi et al. (2015) [20].

The APP Gasplasma process is a combination of two distinct thermal process steps. The first is a fluidised bed gasification process in which steam and oxygen are used as oxidants in the partial oxidation of the waste derived fuel, rather than the anaerobic pyrolysis conditions that characterise indirect gasification processes; accordingly, lower levels of methane and lower levels of higher hydrocarbons are produced by the fluidised bed gasifier, which is operated at $750-800{ }^{\circ} \mathrm{C}$. In the second step, the crude syngas produced by the bubbling bed gasifier is exposed to extreme conditions $\left(\mathrm{T} \sim 1200^{\circ} \mathrm{C}\right)$ in a separate plasma converter. The plasma converter completely degrades 
complex hydrocarbons and tars reducing them to simple chemicals - the oxides of carbon, plus hydrogen constitute the syngas stream along with simple inorganic contaminants such as hydrogen sulphide and hydrogen chloride which are readily removed with conventional gas scrubbing techniques. This includes a dry filter (ceramic filter unit with sodium bicarbonate dosing and activated carbon) followed by acid and alkaline wet scrubbers. Water condenses from the syngas as it is cooled below the dew point when entering the first scrubber. The water mixed with an acid solution dissolves almost all the nitrogenous compounds (mostly ammonia), while the alkaline liquor removes chloride, fluoride, and sulphur gases present, as well some of the $\mathrm{CO}_{2}$. It is important to note that the converter also breaks down covalently bound organic sulphur (e.g. thiophenes, thioles, $\mathrm{CS}_{2}$, etc.) which cannot be removed by conventional scrubbers and would be particularly detrimental in this system due to the high sensitivity of synthesis catalysts to sulphur in all its forms. This is reported to be one of the main obstacles in the use of waste fuels for SNG production [27].

An additional key requirement for the product gas is a low level of inerts such as $\mathrm{N}_{2}$ and argon. These are difficult to separate from methane without resorting to costly cryogenic processes and therefore it is preferable to limit them at the gasification stage. The chosen design approach to this challenge is to use high purity (>99.5\%) oxygen in the gasification process for SNG production as opposed to air, i.e. normally used in gasification for power production.

The close coupling of the two conversion stages seems to successfully overcome the first issue highlighted in this paper, i.e. processing high throughputs of waste materials whilst simultaneously permitting the production of a consistent quantity of clean syngas. The second aspect to be proven is the suitability of the syngas for bio-SNG generation at industrially relevant conditions. In order to separate the operation of the Gasplasma and the bio-SNG pilot plants, syngas from the Gasplasma process is compressed to 50 bar and stored in four identical gas storage vessels capable of supplying gas for approximately 7 days (168 hours) of continuous operation. A simplified schematic of the bioSNG pilot plant is shown in Figure 12.

In the bio-SNG process, clean syngas flows through a high temperature (HT) water gas shift reactor and a series of fixed-bed adiabatic catalytic reactors (MTH) of same configuration and progressively higher Nickel content. Between reactors, heat is removed from the system in conventional heat exchange equipment. As the flow progresses through the series of reactors and exchangers and the bulk of the syngas is converted to methane, the temperature of the process gas is progressively lowered, finally resulting in an adequately reduced temperature favourable for achieving a high conversion efficiency of hydrogen and carbon oxides to methane. Upon condensation of water, $\mathrm{CO}_{2}$ is the second dominant component along with methane. Removal of carbon dioxide from the product stream can be performed by a number of commercially available processes, including chemical or physical solvents as well as pressure swing adsorption (PSA) [47]. Each process has different selectivity towards $\mathrm{CO}_{2}$ removal, with some chemical approaches being highly selective. Monoethanolamine (MEA) sorbents, for example, can capture about $75 \%-95 \% \mathrm{CO}_{2}$ from postcombustion gas to yield a fairly pure (>99\%) $\mathrm{CO}_{2}$ product stream [48]. Selection of any particular option is an economic question in the context of the plant operations. For the pilot plant, a PSA system supplied by Carbotech (Germany) was used. Key attributes of the PSA include its flexibility (important on experimental plants) and its use of pressure swings for adsorber regeneration, with associated compression load. PSA also offers the prospect of being able to separate other 
components, particularly $\mathrm{N}_{2}$, and potentially unreacted $\mathrm{H}_{2}$ and $\mathrm{CO}$, which may be beneficial as a tool for meeting gas quality specification.

The entire plant has been specifically designed to operate over a broad range of conditions, with flows of up to $51 \mathrm{~kW}$ (of thermo-chemical energy) of methane product gas, and at reaction pressures between 1 and 20 bar. For this preliminary study, however, the plant was run at atmospheric pressure. The gas composition was continuously monitored across the whole plant using an IR Xentra 4210 analyser and a Gasmet Fourier Transform Infrared (FTIR) Continuous Emissions Measuring System (CEMS). Specific gas species analysed in this study included: $\mathrm{CO}, \mathrm{CO}_{2}, \mathrm{H}_{2} \mathrm{O}, \mathrm{NOx}$, SOx, COS, HF, $\mathrm{HCl}$ and a number of organic species (i.e. $\mathrm{CH}_{4}, \mathrm{C}_{2} \mathrm{H}_{4}, \mathrm{C}_{2} \mathrm{H}_{6}, \mathrm{C}_{3} \mathrm{H}_{8}, \mathrm{C}_{6} \mathrm{H}_{14}, \mathrm{C}_{6} \mathrm{H}_{5} \mathrm{OH}, \mathrm{C}_{6} \mathrm{H}_{6}$ and $\mathrm{C}_{6} \mathrm{H}_{5} \mathrm{CH}_{3}$ ). In the PSA unit a Siemens Ultramat 23 for $\mathrm{CO} / \mathrm{CO}_{2}$ and a Siemens Calormat for Hydrogen were also used. More detailed analysis was undertaken for the syngas stored in the vessels to detect any potential residual contaminant. Volatile species, including organic sulphur and residual $\mathrm{C}+$ hydrocarbons, were thermally desorbed from trap concentrators on the purge line of each vessel, separated by GC and analysed offsite by a positive ion electron impact mass spectrometer (MS), as detailed in [21]. However, it must be noted that, due to efficient cleaning and the intermediate fourstage compression stage with condensate removal, these species were never present at significant levels (see Table 8 in next Section).

\subsection{Plant operation and comparison of results}

A typical UK refuse derived fuel (RDF) was initially fed to the Gasplasma process to transform the wastes to a hydrogen-rich syngas, as described in other publications [21], [49]. The composition and characteristics of the RDF used in this study are reported in Table 7.

The prepared waste used for the experiments came from a number of municipal solid waste treatment facilities in floc form, in a density range of $150-250 \mathrm{~kg} \mathrm{~m}^{-3}$ and particle size between 10 and $25 \mathrm{~mm}$.

The produced syngas was then cooled, cleaned and stored (as described in previous section) to produce the syngas provided to the bio-SNG process. The composition of the syngas reported in Table 8 shows that the two-stage fluid bed-plasma process is particularly suitable in providing a syngas free from trace sulphur species and unsaturated hydrocarbons that are known to be detrimental to nickel activity. The $\mathrm{CO}_{2}$ level in the stored syngas was enhanced in the high temperature (HT) shift reactor as an effect of the WGS reaction. Differently from other processes, post-shift syngas is then fed to the methanation reactor (MTH-1) without prior $\mathrm{CO}_{2}$ removal. Although it dilutes the reactants, $\mathrm{CO}_{2}$ has an important effect in suppressing carbon formation, dampening the temperature increase and influencing the WGS equilibrium such that it increases the selectivity of $\mathrm{CO}$ to methane [50]. The reacting syngas goes through several methanation and cooling steps, needed to transform the syngas to a methane-rich gas that can then be further purified to produce the bio-SNG. This section will only focus on the first methanation reactor (MTH-1) for validation purposes.

The initial batch of catalyst in the first methanator used the same $8 \% \mathrm{Ni}$ catalyst tested on the lab scale unit in its original size, and same inert packing dilution. Prior to methanation, the system was heated to a temperature of $430^{\circ} \mathrm{C}$ by $\mathrm{N}_{2}$, before $\mathrm{H}_{2}$ was introduced to reduce the $8 \% \mathrm{Ni}$ catalyst. Due 
to the thermal inertia of the catalyst bed, several hours were needed for the catalyst to reach its operating temperature. The experiment was started by changing the gas mixture to the desired composition. Post-shift syngas was then introduced into the MTH-1 reactor at 1 bar, initially diluted with $70 \%$ of $\mathrm{N}_{2}$, and methane was measured in the outlet stream by FTIR analysis (Table 9).

The high dilution with nitrogen was used at the beginning as thermal ballast and to avoid, especially during the first 15-30 minutes when the fresh catalyst has an abnormally high activity (see Figure 2), an excessive rise in temperature that would activate the in-built thermal safety trip of the system. Dilution was progressively reduced until $\sim 10 \% \mathrm{~N}_{2}$ was present in the feed gas (Figure 13), and temperature controlled to below $500{ }^{\circ} \mathrm{C}$. As a consequence, space velocity was also decreased accordingly, from $40,000 \mathrm{~h}^{-1}$ at $70 \%$ dilution to $10,600 \mathrm{~h}^{-1}$ at less than $10 \%$ dilution.

In order to simulate the pilot reactor using the same model developed in Section 3, the intrinsic kinetic equations derived should be combined with the formulation of the diffusional limitations encountered when larger catalyst particles are used. To this end, the pore diffusion effect was evaluated by using the Weisz criterion [51]. As reported by Smith [52], the pore diffusion effects can be neglected if the Thiele modulus is lower than unity:

$$
\frac{d_{c}^{2} r_{C O}^{\prime}}{4\left(P_{C O} / R T\right) D_{e f f}} \leq 1
$$

where $d_{c}$ is the catalyst diameter, $P_{C O}$ is the bulk CO partial pressure (assuming the particle external resistance is negligible), $D_{e f f}$ is the CO effective diffusivity into the pellet, and $r_{C O}^{\prime}$ the rate of reaction of $\mathrm{CO}$ at temperature $T$. Since the system is not isothermal, the Thiele modulus was calculated for the two extreme cases, i.e. at the inlet and outlet temperatures of the reactor $\left(330^{\circ} \mathrm{C}\right.$ and $498{ }^{\circ} \mathrm{C}$, respectively), at the respective gas compositions. Under the experimental conditions described in Table 9, the pore diffusion criterion is always below 1, or even below 0.02 for $\mathrm{T}=330$ ${ }^{\circ} \mathrm{C}$. Hence, we can consider that no pore diffusion limit exists in this case.

From the experimental data it is clear that $\mathrm{N}_{2}$ dilution and the space velocity have an important effect on methane production. Specifically lower GHSV (and nitrogen dilution) values lead to higher methane yields. The same behaviour is confirmed by the model where methane production is investigated at different space velocities with no additional $\mathrm{N}_{2}$, as shown in Figure 14.

It is interesting to note that when the space velocity is sufficiently low (i.e. $<5,000 \mathrm{~h}^{-1}$ ), the rates of methanation and steam reforming are identical, so almost no net change in methane production is observed. When this occurs, kinetic restrictions are avoided by the synergy between high operating temperature and long residence time in the reactor, so the system closely approaches thermodynamic equilibrium. Conversely, excessive space velocities $\left(>20,000 \mathrm{~h}^{-1}\right)$ do not allow sufficient residence time for methanation to occur, and no further $\mathrm{CO}$ is converted to methane.

During steady state operation, methane was produced in the first reactor at rates varying from 12 to $26 \mathrm{kWth}$, and at concentrations of $9-12 \%$ in volume (when normalised for $\mathrm{N}_{2}$ content), equating to $30-33 \%$ CO conversion (see Fig. 15). This is slightly lower than the equilibrium value, but still compares favourably with the $22 \mathrm{kWth}$ rate of production predicted by the model for the first reactor (see Table 10). The enhanced performance achieved in the pilot plant may be due to the 
system thermal losses that permit the reaction to be carried out at lower than adiabatic temperature.

The comparison between model predictions and pilot plant results is reasonably fair, with the predicted values deviating from the experimental results within the range of $5-10 \%$; the noted differences are likely due to syngas flow uncertainties and thermal losses within the system rather than from the predictive model. Given the size and configuration of the pilot plant and the inherent variability of waste-derived syngas uncertainties are to be expected. Higher margins of errors were found for $\mathrm{N}_{2}$ and $\mathrm{H}_{2} \mathrm{O}$, which also tended to fluctuate significantly over time. The reason for this was mainly related to the limitations of steam injection system and FTIR measurement $\left(\mathrm{H}_{2}\right.$ and $\mathrm{N}_{2}$ were calculated by mass balance as not directly measurable with infrareds techniques).

If significantly larger particle sizes have to be used (e.g. in a large scale industrial reactor), pore diffusion effects might become important and attempts to use the unmodified model should be discouraged. The occurrence of many simultaneous reactions (with common components) together with multicomponent surface and diffusion phenomena would be a significant undertaking worthy of further research.

Due to its mild activity and ease of control in operation, the $8 \% \mathrm{Ni}$ catalyst proved to be suitable for the first reaction stage of the bio-SNG pilot plant, with no need for product gas recycle loops or heat extraction systems. This would ensure that up to $44 \%$ of total methanation could occur in a single once through reactor (see Figure 16), along with a better control of the reaction at the initial stage, which is the most critical. This was also due to the significant presence of $\mathrm{CO}_{2}$ in the syngas, as result from autothermal gasification of RDF and high temperature shift. A higher activity catalyst would be utilised to methanate higher levels of $\mathrm{CO}$ in the following two stages, which operate at lower temperatures. When the methanation is carried out at lower temperature, the methane yield is correspondingly higher. As such, the syngas methanation can be operated adiabatically without gas recycles and in three simple vessels without internal cooling, and still achieve $>95 \%$ conversion of co.

The SNG mass flow from process represents only some c. $17 \%$ of the syngas mass flow. The reduction in flow is largely attributable to the removal of large quantities inert products (e.g. carbon dioxide and water) from the stream in both the reaction and separation stages. As a consequence, the bulk of the energy content is held within the SNG product gas stream. The energy conversion efficiency from stored syngas to SNG on the pilot plant is between 70 and $75 \%$ (on a net calorific value basis). Taking into account the cold gas efficiency of the gasification stage the projected energy conversion efficiency from incoming RDF to SNG is well above $60 \%$. This represents the potential combustion energy available in the SNG relative to that contained in the RDF feedstock, which equates to c. $2.5 \mathrm{MW}$ of gross calorific energy per tonne of feedstock, and to the plasma thermal input normalized for a full scale system on account of the disproportionally high inherent thermal losses of the small pilot plasma unit [20]. If energy integration is applied, the energy demand of the process is completely covered by the heat generated in the exotherm process. The excess thermal energy can be used in various ways (e.g., electricity generation via steam turbine, district heating, etc.), so to make the total energy efficiency very competitive. 


\section{Conclusions}

To determine the kinetic behaviour and operating parameters of a commercial methanation catalyst, using a high $\mathrm{CO}-\mathrm{CO}_{2}$ gas feed in a once through configuration, a series of catalyst test runs were carried out utilising a lab scale reactor. A plug flow kinetic system was adopted to correlate the laboratory data and define the rate of reaction. The catalyst used for the series of test runs was an $8 \% \mathrm{Ni}$ commercial methanation catalyst. The model, comprising water gas shift and methanation reactions, along with their reverse reactions, was used for realistic modelling of the methanation process using waste derived syngas and to confine the range of operation parameters to be tested during the pilot scale tests in the first reactor of a bio-SNG plant in Swindon (UK). This information was, in fact, part of the technical and economic feasibility of thermal gasification of waste to bioSNG, through the operation of the pilot plant in Swindon to take a waste-derived syngas and upgrading this to GSMR (Gas Safety Management Regulation) compliant SNG gas suitable for entry to the UK gas distribution network.

There is close correlation between the observed and predicted values of the gas composition exiting the first methanation reactor, although the actual level of $\mathrm{CO}$ is still $2 \%$ below the theoretical value while the $\mathrm{CO}_{2}$ level is $1.5 \%$ lower. The noted differences are likely due to flow and syngas composition uncertainties rather than from the predictive model. Given the size and configuration of the pilot plant and the inherent variability of real syngas, uncertainties are to be expected and unavoidable. Production rates on the pilot plant compared highly favorably to the model predictions, where conversion of carbon monoxide in excess of $30 \%$ were predicted, with total system outputs of $26 \mathrm{kWth}$ of methane predicted to be generated across the first reactor only.

The high degree of correlation between model predictions, lab scale tests and pilot plant results for the first stage methanation investigated in this study gives a confidence that the same power law model can be used to predict the outputs of the second and third methanators, provided that kinetic parameters are modified for higher Nickel content in the catalyst. Furthermore, the results show that the catalysts were performing as expected when using a waste-derived syngas when compared to models derived from works using high purity bottled gases. This specific aspect has to be related to the high syngas purity obtained with the use of two-stage gasification systems for bio-SNG applications and offers a generous prospect for its utilization at industrial scale. Future research will focus on further observations on the integrated system, possible catalyst deactivation during long term ( $>2000 \mathrm{~h}$ ) trials, and effect of mass transfer and pore diffusion limitations on larger catalyst particle size. The results of this study are expected to be an important component for the overall design, optimization and control of commercial once-through methanation reactor elements and process system configuration for bio-SNG production from waste at larger scale.

\section{Acknowledgements}

The authors wish to acknowledge the GoGreenGas consortium for the support provided through the experimental phase and pilot plant demonstration. The project was sponsored from both Ofgem's Network Innovation Competition and the European BESTF-ERANET programme. The assistance 
provided by Andrew Holt from Catal International Ltd for the operation of the lab rig used in this work is also gratefully acknowledged.

\section{References}

[1] S. Wirth and J. Markard, "Context matters: How existing sectors and competing technologies affect the prospects of the Swiss Bio-SNG innovation system," Technol. Forecast. Soc. Change, vol. 78, no. 4, pp. 635-649, 2011.

[2] C. M. van der Meijden, H. J. Veringa, and L. P. L. M. Rabou, "The production of synthetic natural gas (SNG): A comparison of three wood gasification systems for energy balance and overall efficiency," Biomass and Bioenergy, vol. 34, no. 3, pp. 302-311, 2010.

[3] S. Rönsch and M. Kaltschmitt, "Bio-SNG production - concepts and their assessment," Biomass Convers. Biorefinery, vol. 2, no. 4, pp. 285-296, 2012.

[4] K. M. Holmgren, T. S. Berntsson, E. Andersson, and T. Rydberg, "The influence of biomass supply chains and by-products on the greenhouse gas emissions from gasification-based bio-SNG production systems," Energy, vol. 90, pp. 1-15, 2014.

[5] B. Steubing, R. Zah, and C. Ludwig, "Life cycle assessment of SNG from wood for heating, electricity, and transportation," Biomass and Bioenergy, vol. 35, no. 7, pp. 2950-2960, 2011.

[6] D. Barisano, G. Canneto, F. Nanna, A. Villone, E. Alvino, M. Carnevale, and G. Pinto, "Production of gaseous carriers via biomass gasification for energy purposes," in Energy Procedia, 2014, vol. 45, pp. 2 11.

[7] H. Habazaki, M. Yamasaki, B.-P. Zhang, A. Kawashima, S. Kohno, T. Takai, and K. Hashimoto, "Comethanation of carbon monoxide and carbon dioxide on supported nickel and cobalt catalysts prepared from amorphous alloys," Appl. Catal. A Gen., vol. 172, no. 1, pp. 131-140, 1998.

[8] L. Jürgensen, E. A. Ehimen, J. Born, J. B. Holm-Nielsen, and D. Rooney, "Influence of trace substances on methanation catalysts used in dynamic biogas upgrading," Bioresour. Technol., vol. 178, pp. 319322, 2015.

[9] Y. Zhu, X. Li, D. Ji, and H. Liu, "Study on the carbon-methanation and catalytic activity of Ru/Ac for ammonia synthesis," Chinese J. Chem. Eng., vol. 12, no. 3, pp. 384-387, 2004.

[10] R. W. R. Zwart, H. Boerrigter, E. P. Deurwaarder, C. M. van der Meijden, and S. V. B. Paasen, "Production of Synthetic Natural Gas (SNG) from Biomass," p. 62, 2006.

[11] J. Kopyscinski, T. J. Schildhauer, and S. M. A. Biollaz, "Production of synthetic natural gas (SNG) from coal and dry biomass - A technology review from 1950 to 2009," Fuel, vol. 89, no. 8, pp. 1763-1783, 2010.

[12] S. Rönsch, J. Schneider, S. Matthischke, M. Schlüter, M. Götz, J. Lefebvre, P. Prabhakaran, and S. Bajohr, "Review on methanation - From fundamentals to current projects," Fuel, vol. 166. pp. 276-296, 2016. 
[13] J. Agerborg and E. Lingehed, "Integration of Power-to-Gas in Gasendal and GoBiGas," Publications.Lib.Chalmers.Se, pp. 1-70, 2013.

[14] M. D. Kaufman-Rechulski, T. J. Schildhauer, and S. M. A. Biollaz, "Organic sulfur compounds in the producer gas from wood and grass gasification," in 19th European Biomass Conference \& Exhibition, 2011, pp. 1625-1627.

[15] R. W. R. Zwart, "Gas cleaning downstream biomass gasification Status Report 2009," no. JUNE, 2009.

[16] M. In, C. Gasification, J. P. Strakey, A. J. Forney, and W. P. Haynes, "Methanation in coal gasification processes," Pittsburgh Energy Res. Cent., 1975.

[17] a. Bosmans, I. Vanderreydt, D. Geysen, and L. Helsen, "The crucial role of Waste-to-Energy technologies in enhanced landfill mining: A technology review," J. Clean. Prod., vol. 55, pp. 10-23, 2013.

[18] M. Materazzi, P. Lettieri, L. Mazzei, R. Taylor, and C. Chapman, "Fate and behavior of inorganic constituents of RDF in a two stage fluid bed-plasma gasification plant," Fuel, vol. 150, pp. 473-485, Jun. 2015.

[19] U. Arena, L. Zaccariello, and M. L. Mastellone, "Fluidized bed gasification of waste-derived fuels," Waste Manag., vol. 30, no. 7, pp. 1212-1219, 2010.

[20] M. Materazzi, P. Lettieri, R. Taylor, and C. Chapman, "Performance analysis of RDF gasification in a two stage fluidized bed-plasma process.," Waste Manag., Jul. 2015.

[21] M. Materazzi, P. Lettieri, L. Mazzei, R. Taylor, and C. Chapman, "Reforming of tars and organic sulphur compounds in a plasma-assisted process for waste gasification," Fuel Process. Technol., vol. 137, pp. 259-268, Sep. 2015.

[22] L. a. Hansen, F. J. Frandsen, K. Dam-Johansen, H. S. Sørensen, and B. J. Skrifvars, "Characterization of ashes and deposits from high-temperature coal-straw co-firing," Energy and Fuels, vol. 13, no. 4, pp. 803-816, 1999.

[23] U. Arena, "Process and technological aspects of municipal solid waste gasification. A review," Waste Manag., vol. 32, no. 4, pp. 625-639, 2012.

[24] J. Gao, Q. Liu, F. Gu, B. Liu, Z. Zhong, and F. Su, "Recent advances in methanation catalysts for the production of synthetic natural gas," RSC Adv., vol. 5, no. 29, pp. 22759-22776, 2015.

[25] P. Panagiotopoulou, D. I. Kondarides, and X. E. Verykios, "Selective methanation of CO over supported Ru catalysts," Appl. Catal. B Environ., vol. 88, no. 3-4, pp. 470-478, 2009.

[26] C. Courson, L. Udron, D. Swierczynski, C. Petit, and A. Kiennemann, "Hydrogen Production from Biomass Gasification on Nickel Catalysts: Tests for Dry Reforming of Methane," Catal. Today, vol. 76, no. 1, pp. 75-86, 2002.

[27] I. Czekaj, F. Loviat, F. Raimondi, J. Wambach, S. Biollaz, and A. Wokaun, "Characterization of surface processes at the Ni-based catalyst during the methanation of biomass-derived synthesis gas: X-ray photoelectron spectroscopy (XPS)," Appl. Catal. A Gen., vol. 329, pp. 68-78, 2007.

[28] C. H. Bartholomew, "Mechanism of catalyst deactivation.," Appl. Catal. A Gen., vol. 212, pp. 17-60, 2001. 
[29] M. Mozaffarian, H. Boerrigter, and E. P. Deurwaarder, "BIOMASS AND WASTE-RELATED SNG PRODUCTION TECHNOLOGIES: Technical, economic and ecological feasibility," 2nd World Conf. Technol. Exhib. Biomass Energy, Ind. Clim. Prot., no. April, 2004.

[30] L. Romano and F. Ruggeri, "Methane from syngas - Status of Amec Foster Wheeler VESTA technology development," in Energy Procedia, 2015, vol. 81, pp. 249-254.

[31] C. H. Bartholomew, "Carbon Deposition in Steam Reforming and Methanation," Catal. Rev., vol. 24, no. 1, pp. 67-112, 1982.

[32] J. Gao, Y. Wang, Y. Ping, D. Hu, G. Xu, F. Gu, and F. Su, "A thermodynamic analysis of methanation reactions of carbon oxides for the production of synthetic natural gas," RSC Adv., vol. 2, no. 6, pp. 2358-2368, 2012.

[33] M. Agnelli, H. M. Swaan, C. Marquez-Alvarez, G. A. Martin, and C. Mirodatos, "CO hydrogenation on a nickel catalyst - II. A mechanistic study by transient kinetics and infrared spectroscopy," J. Catal., vol. 175, pp. 117-128, 1998.

[34] D. W. Goodman, R. D. Kelley, T. E. Madey, and J. T. Yates, "Kinetics of the hydrogenation of CO over a single crystal nickel catalyst," J. Catal., vol. 63, no. 1, pp. 226-234, 1980.

[35] J. G. Xu and G. F. Froment, "Methane Steam Reforming, Methanation and Water-Gas Shift .1. Intrinsic Kinetics," Aiche J., vol. 35, no. 1, pp. 88-96, 1989.

[36] M. S. Batista, E. I. Santiago, E. M. Assaf, and E. A. Ticianelli, "Evaluation of the water-gas shift and CO methanation processes for purification of reformate gases and the coupling to a PEM fuel cell system," J. Power Sources, vol. 145, no. 1, pp. 50-54, 2005.

[37] J. Zhang, N. Fatah, S. Capela, Y. Kara, O. Guerrini, and A. Y. Khodakov, "Kinetic investigation of carbon monoxide hydrogenation under realistic conditions of methanation of biomass derived syngas," Fuel, vol. 111, pp. 845-854, 2013.

[38] T. Van Herwijnen, H. Van Doesburg, and W. A. De Jong, "Kinetics of the methanation of CO and CO2 on a nickel catalyst," J. Catal., vol. 28, no. 3, pp. 391-402, 1973.

[39] R. Z. C. van Meerten, J. G. Vollenbroek, M. H. J. M. de Croon, P. F. M. T. van Nisselrooy, and J. W. E. Coenen, "The kinetics and mechanism of the methanation of carbon monoxide on a nickel-silica catalyst," Appl. Catal., vol. 3, no. 1, pp. 29-56, 1982.

[40] Hou and Hughes, "The kinetics of methane steam reforming over a Ni/alpha-Al2O catalyst," Chem. Eng. J., vol. 82, no. 1-3, pp. 311-328, 2001.

[41] J. a Liu, "Kinetics, catalysis and mechanism of methane steam reforming," Chem. Eng., vol. Master of, no. 82, pp. 311-328, 2006.

[42] S. I. Fujita and N. Takezawa, "Difference in the selectivity of CO and CO2 methanation reactions," Chem. Eng. J., vol. 68, no. 1, pp. 63-68, 1997.

[43] K. Müller, M. Städter, F. Rachow, D. Hoffmannbeck, and D. Schmeißer, "Sabatier-based CO2methanation by catalytic conversion," Environ. Earth Sci., vol. 70, no. 8, pp. 3771-3778, 2013.

[44] W. Wang and J. Gong, "Methanation of carbon dioxide: An overview," Front. Chem. Eng. China, vol. 5, no. 1, pp. 2-10, 2011. 
[45] J. Kopyscinski, T. J. Schildhauer, and S. M. A. Biollaz, "Methanation in a fluidized bed reactor with high initial CO partial pressure: Part II-Modeling and sensitivity study," Chem. Eng. Sci., vol. 66, no. 8, pp. 1612-1621, 2011.

[46] M. A. Vannice, "The catalytic synthesis of hydrocarbons from $\mathrm{H} 2 / \mathrm{CO}$ mixtures over the group VIII metals II. The kinetics of the methanation reaction over supported metals," J. Catal., vol. 37, no. 3, pp. 462-473, 1975.

[47] M. K. Mondal, H. K. Balsora, and P. Varshney, "Progress and trends in CO 2 capture/separation technologies: A review," Energy, vol. 46, no. 1, pp. 431-441, 2012.

[48] A. B. Rao and E. S. Rubin, "A Technical, Economic, and Environmental Assessment of Amine-Based CO 2 Capture Technology for Power Plant Greenhouse Gas Control," Environ. Sci. Technol., vol. 36, no. 20, pp. 4467-4475, 2002.

[49] M. Materazzi, P. Lettieri, L. Mazzei, R. Taylor, and C. Chapman, "Tar evolution in a two stage fluid bedplasma gasification process for waste valorization," Fuel Process. Technol., vol. 128, pp. 146-157, Dec. 2014.

[50] N. R. Parlikkad, S. Chambrey, P. Fongarland, N. Fatah, A. Khodakov, S. Capela, and O. Guerrini, "Modeling of fixed bed methanation reactor for syngas production: Operating window and performance characteristics," Fuel, vol. 107, pp. 254-260, 2013.

[51] P. B. Weisz, "The behaviour of porous catalyst particles in view of internal mass and heat diffusion effects. P. B. Weisz and J. S. Hicks, Chem. Engng Sci. 17: 265-275, 1962," Chem. Eng. Sci., vol. 50, no. 24, pp. 3949-3950, 1995.

[52] J. M. Smith, Chemical Engineering Kinetics, 3rd Editio. McGraw Hill Book Company, 1980. 


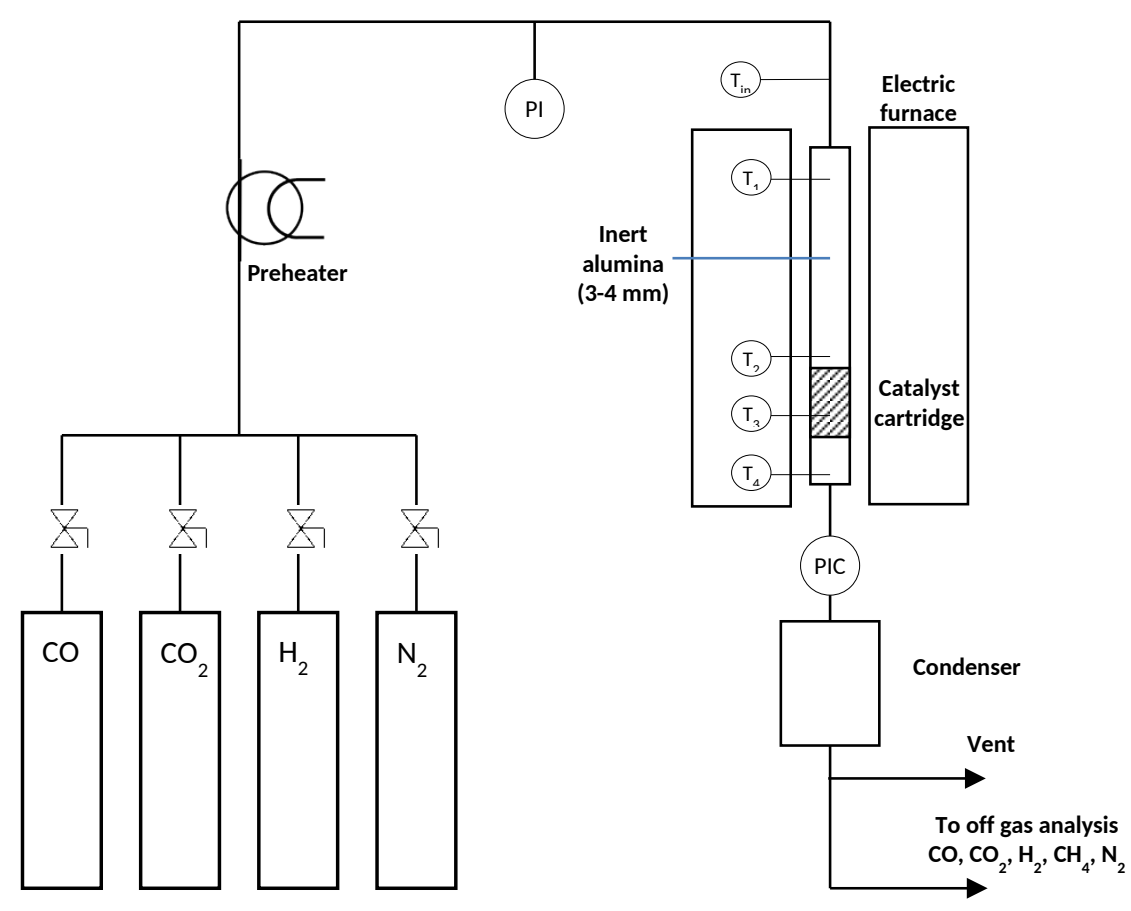

Figure 1: Experimental setup 


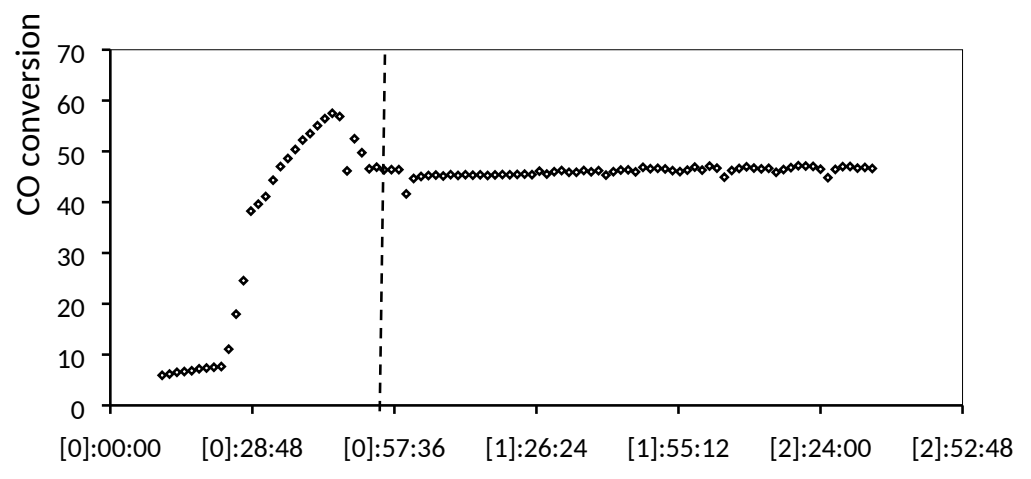

Time on stream (h:mm:ss)

Figure 2: Effect of operating time on the $\mathrm{CO}$ conversion on fresh catalyst at $420^{\circ} \mathrm{C}, \mathrm{P}=1$ bar, $\mathrm{H}_{2} / \mathrm{CO}$ molar ratio $=4.4, \mathrm{GHSV}: 19000 \mathrm{~h}^{-1}$ 


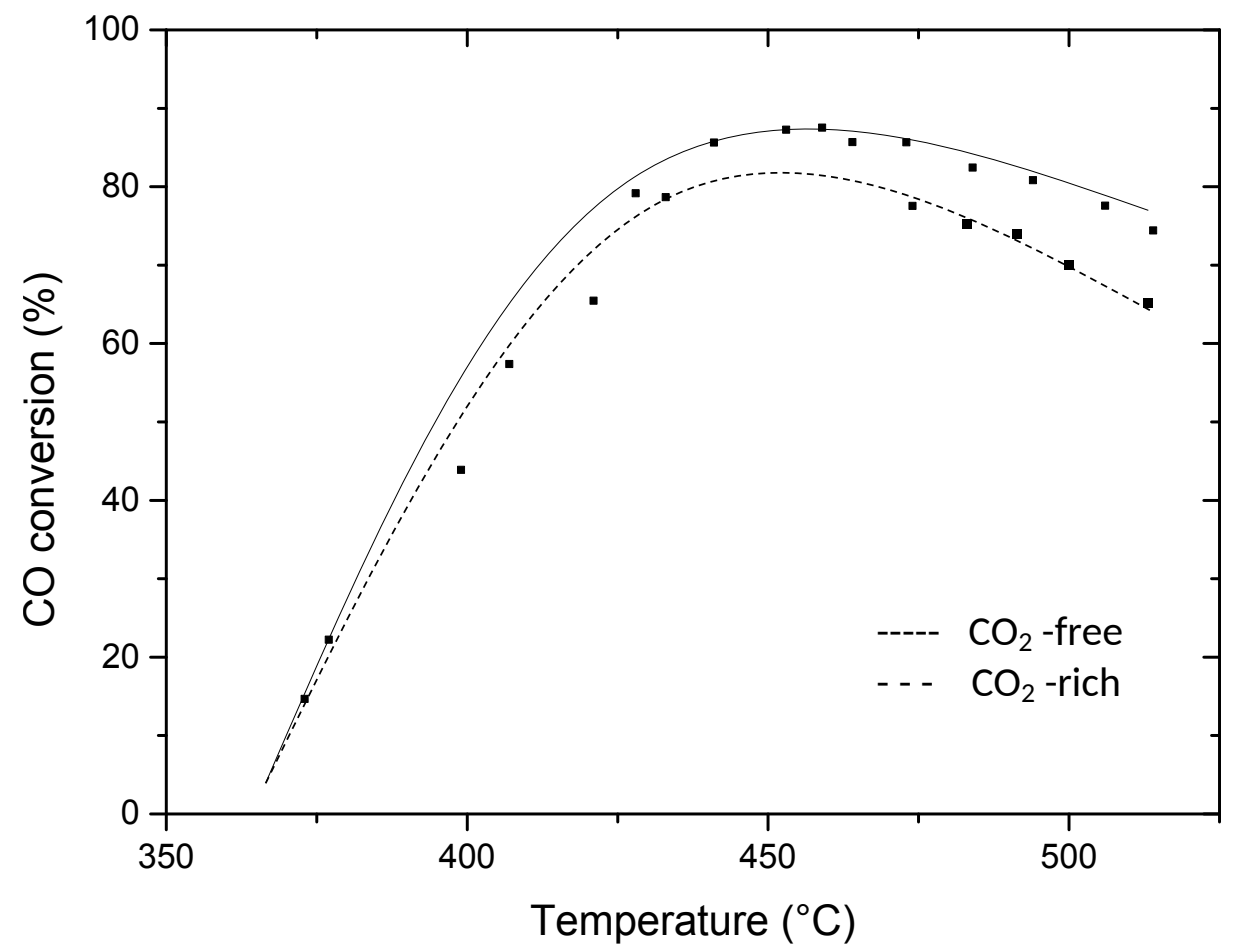

Figure 3: Temperature dependence $\left(300-520^{\circ} \mathrm{C}\right)$ of the CO conversion on a Low Ni/ $\mathrm{Al}_{2} \mathrm{O}_{3}$ catalyst $(12 \mathrm{ml}$; GHSV: $9,000 \mathrm{~h}^{-1}$ ) in different reformate gases: (solid) $\mathrm{CO}=6.1 \% \mathrm{CO}_{2}$ free, (dashed) $\mathrm{CO}=5.8 \% \mathrm{CO}_{2}$-rich. 

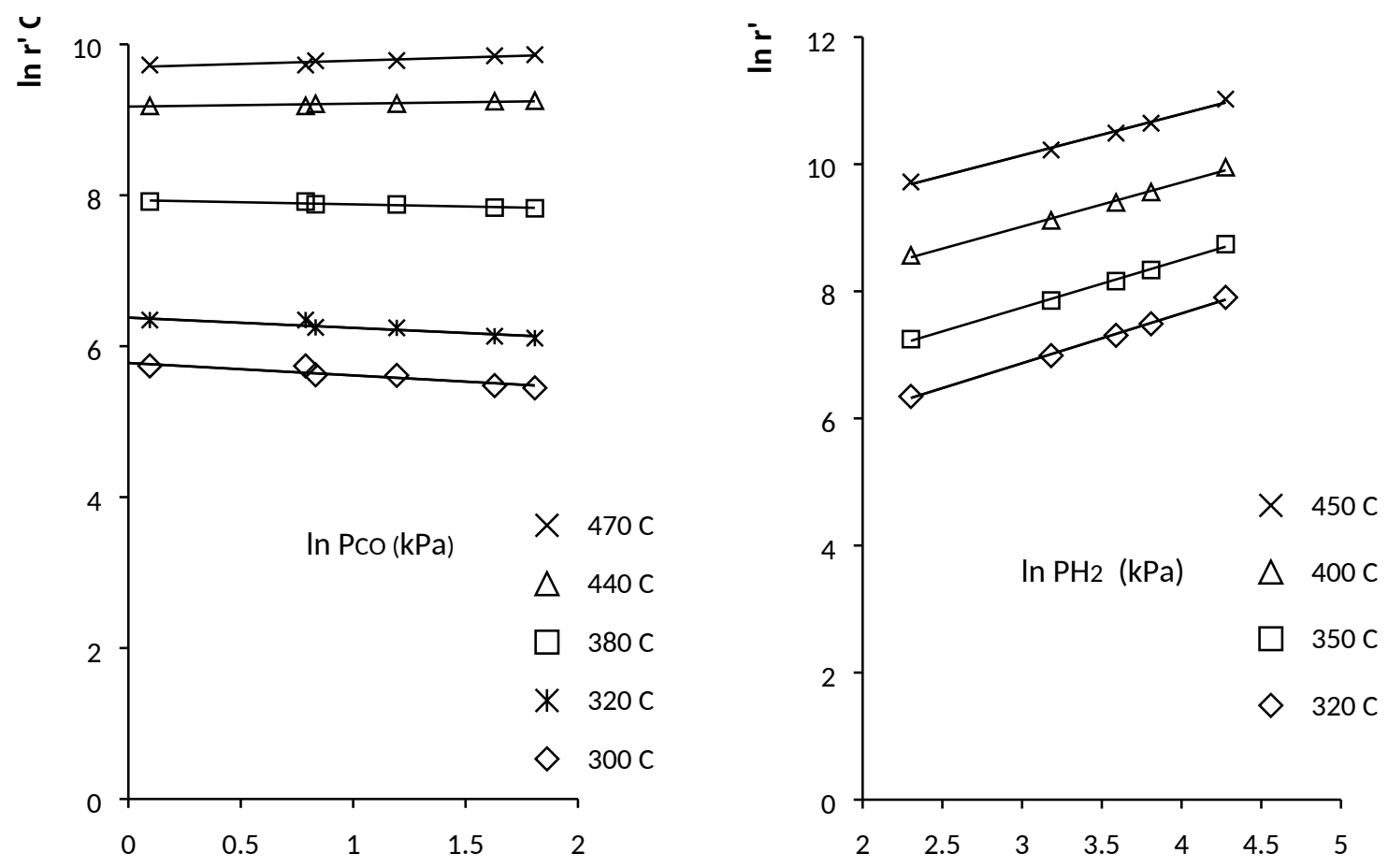

Figure 4: Calculation of $\mathrm{CO}$ and $\mathrm{H}_{2}$ orders for carbon monoxide methanation at different temperatures. Alpha (left) for Runs 1-6, $\mathrm{P}_{\mathrm{H} 2}=0.25$ barg (25 kPa), beta (right) for Runs 6-10, $\mathrm{P}_{\mathrm{cO}}=0.06$ barg (6 kPa). 

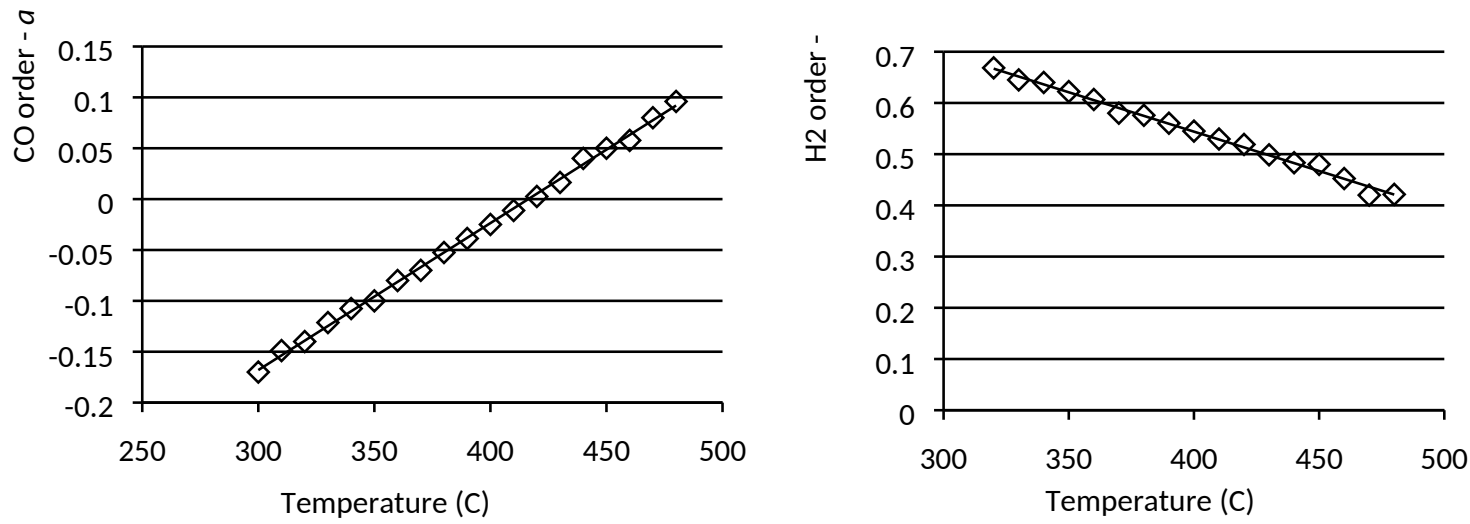

Figure 5: $\mathrm{CO}$ and $\mathrm{H}_{2}$ reaction order for carbon monoxide methanation at different temperatures (Runs 1-10) 

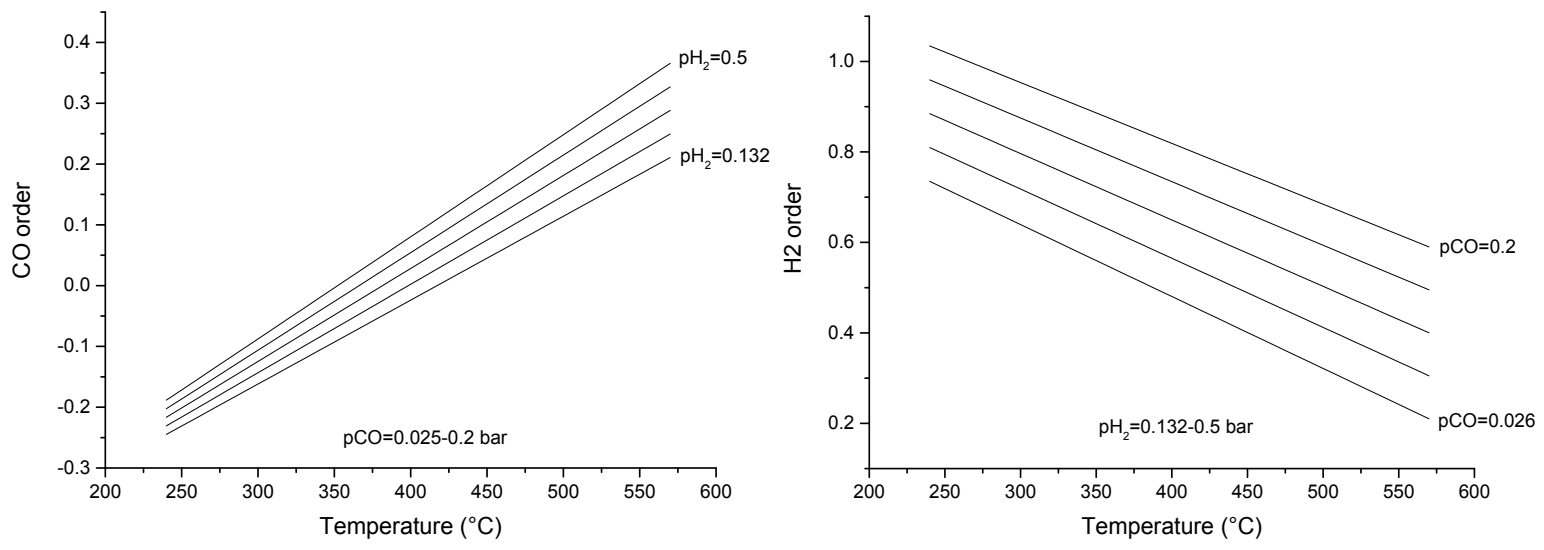

Figure 6: Change in reaction order in $\mathrm{CO}$ (left) and $\mathrm{H}_{2}$ (right) with temperature at different $\mathrm{H}_{2}$ and $\mathrm{CO}$ partial pressures on a similar $5 \%$ Ni catalyst (experimental data and conditions extrapolated from [40]). 


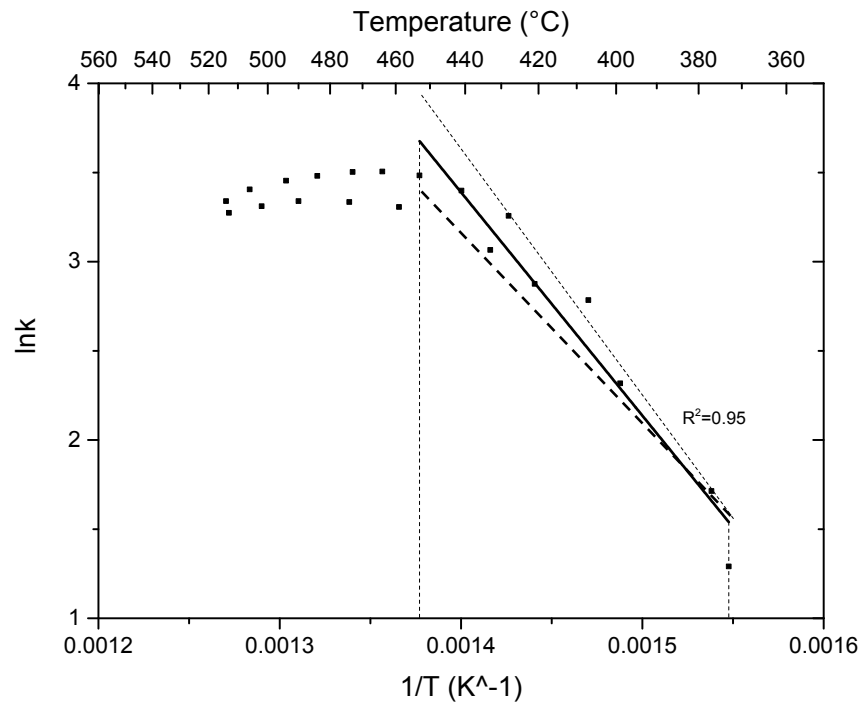

Figure 7: Arrhenius plot for a combination of CO methanation tests (Runs 3-7). 


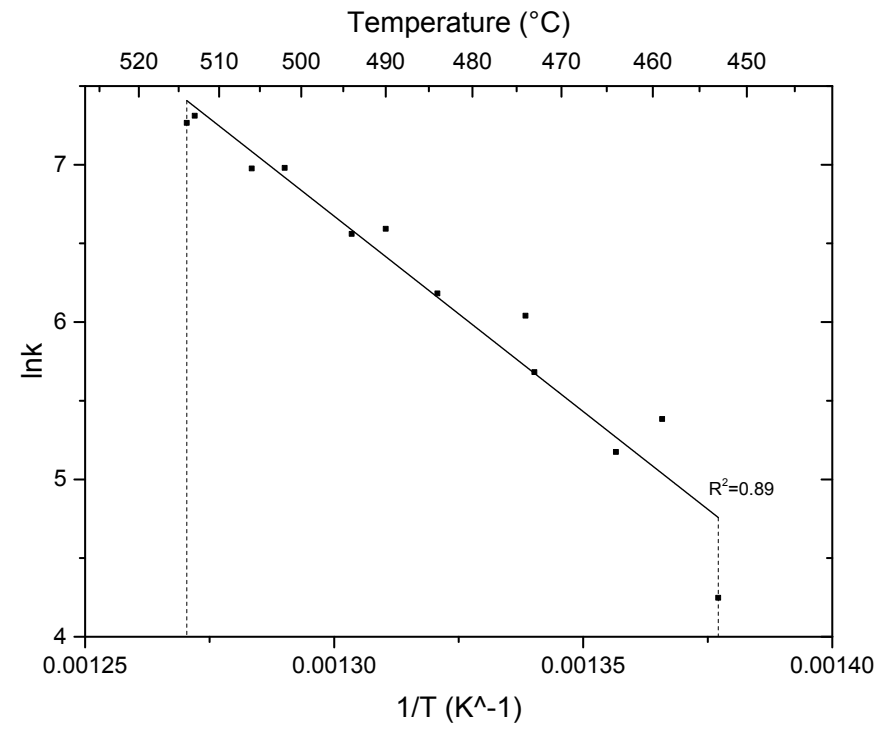

Figure 8: Arrhenius plot for steam reforming data points (Runs 3-7). 

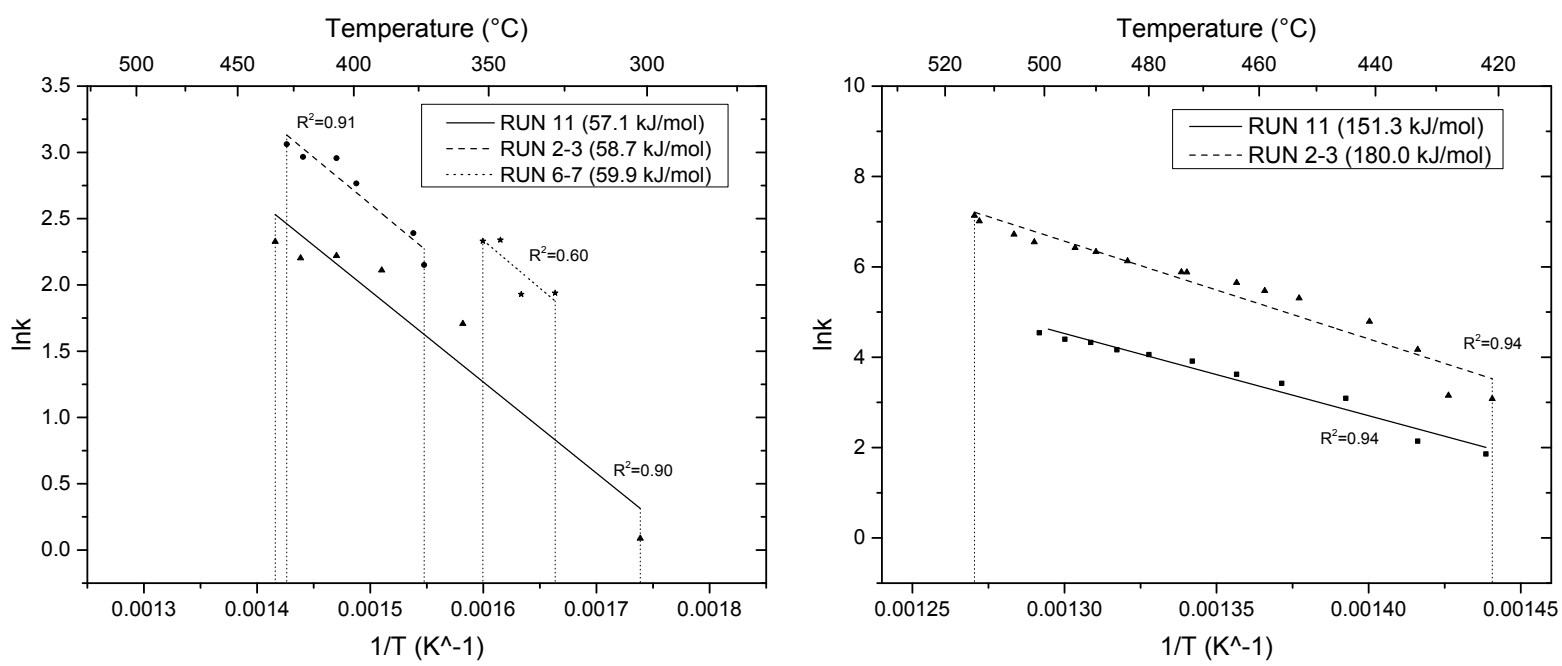

Figure 9: Arrhenius plot for water gas shift (left) and reverse water gas shift (right) (Runs 2, 3, 6, 7, 11). 


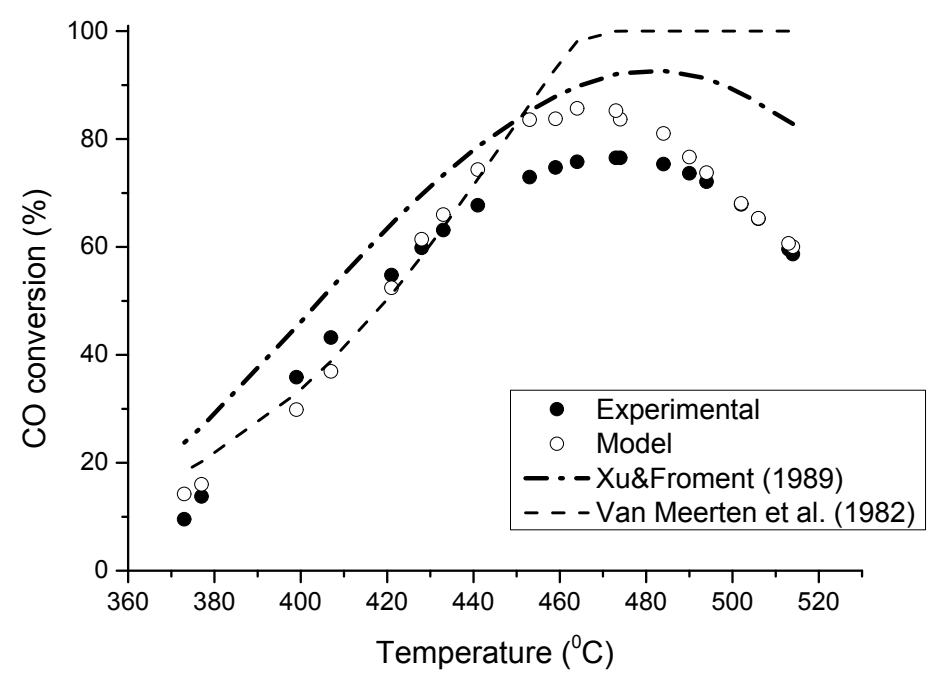

Figure 10: Comparison between experimental results and models predictions (Run 12). 

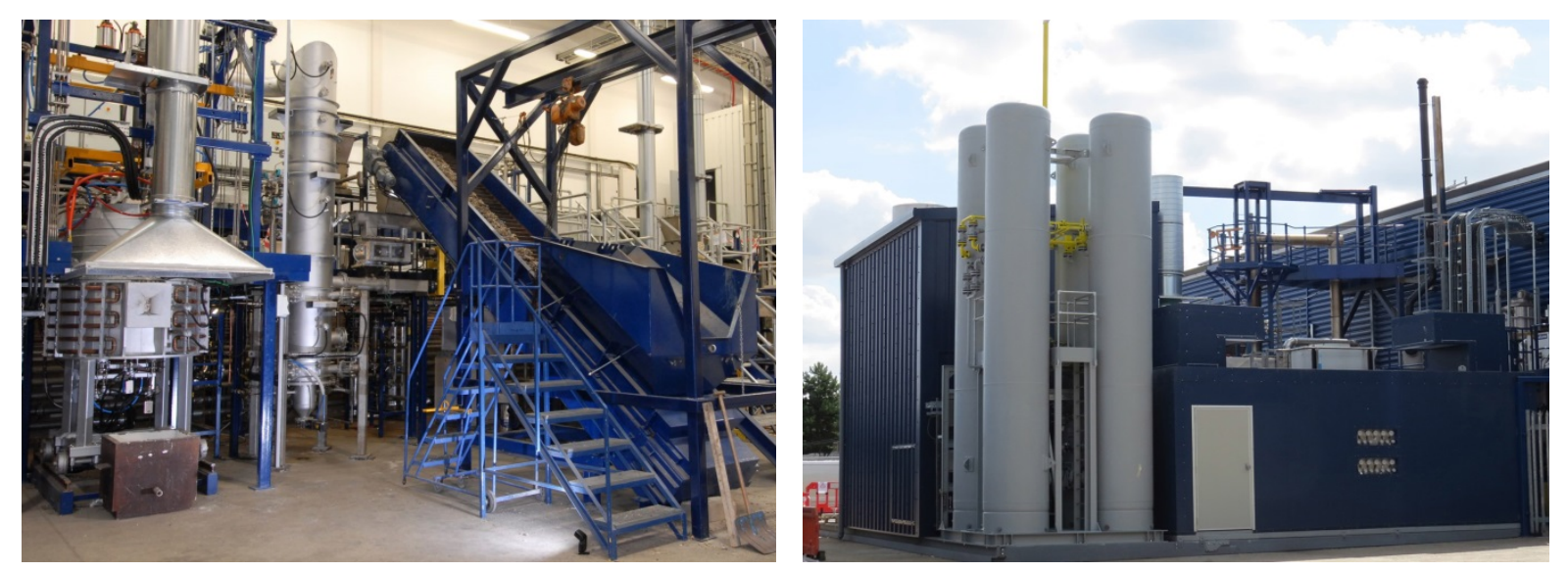

Figure 11: Direct photo of major components of the pilot plant: two-stage fluidised bed and plasma converter for syngas generation (left), syngas storage vessels and bio-SNG facility (right). 


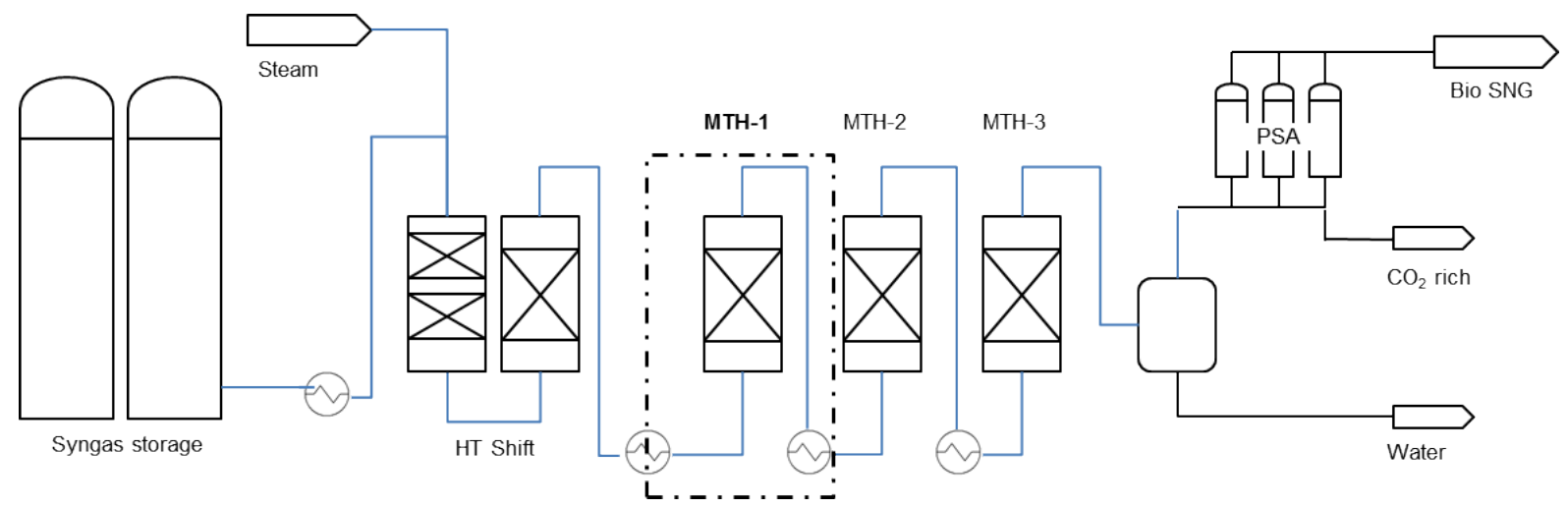

Figure 12: bio-SNG pilot plant schematic. Highlighted area is the first methanation stage (MTH-1) considered in this study. 


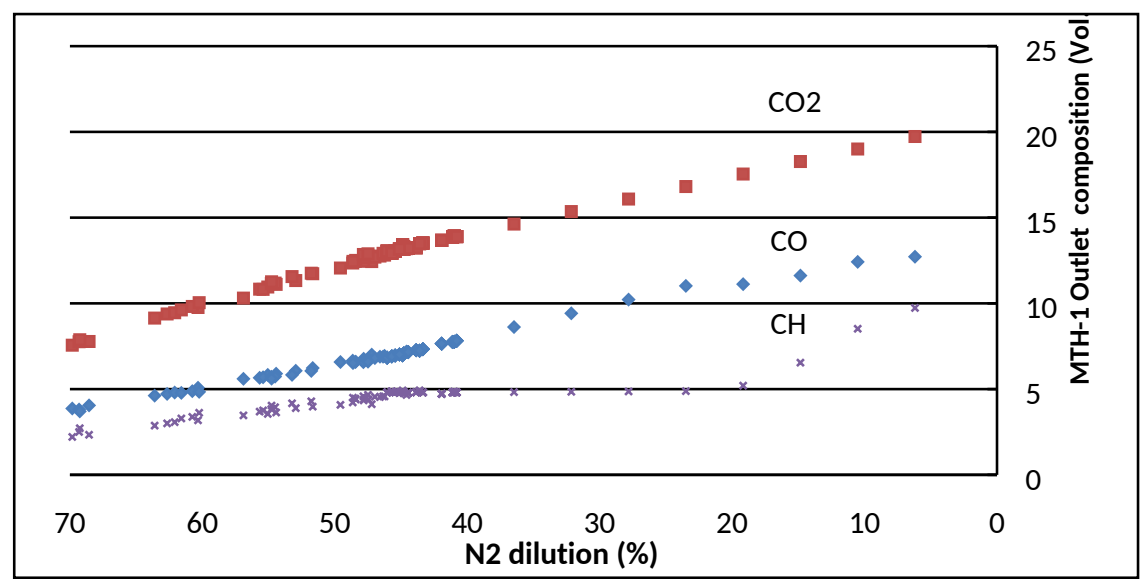

Figure 13: Measured gas composition at the outlet of first methanation reactor (MTH-1) for different $\mathrm{N}_{2}$ dilution 


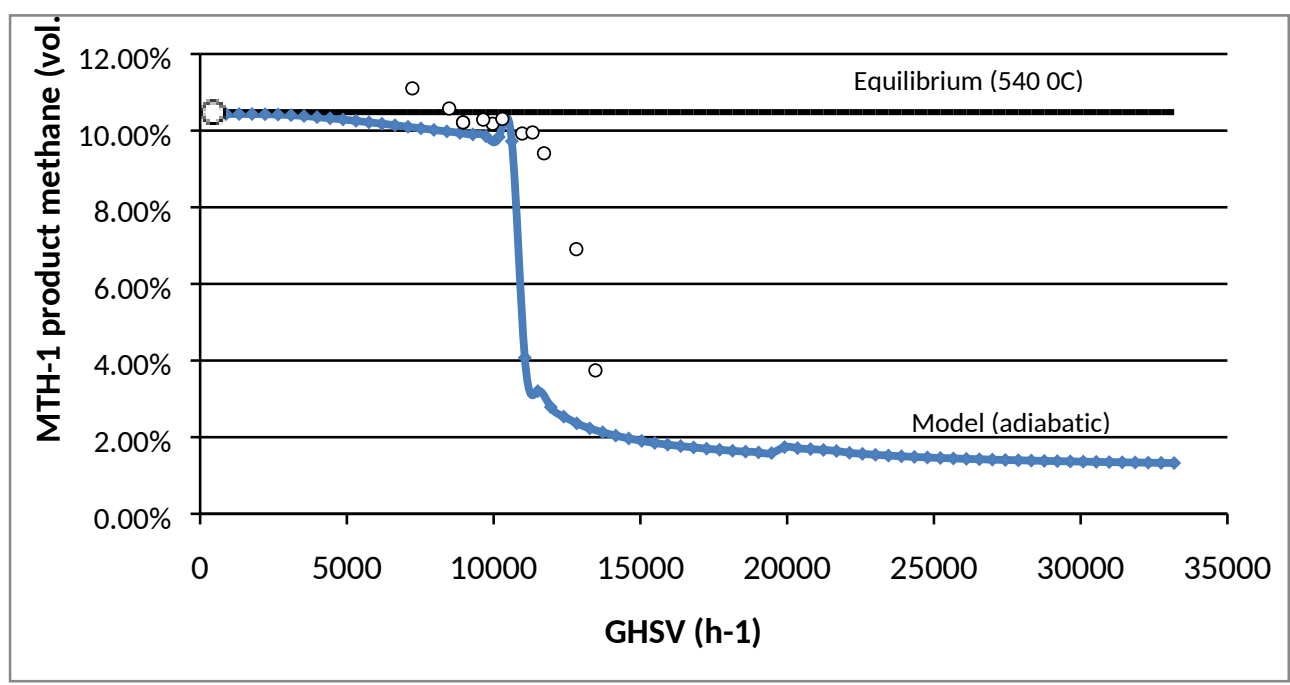

Figure 14: Effect of space velocity on methane production in MTH-1 as predicted by the kinetic model in adiabatic plug flow reactor (inlet temperature: $330^{\circ} \mathrm{C}$ ). Circles represent experimental results gathered from pilot plant trials. 


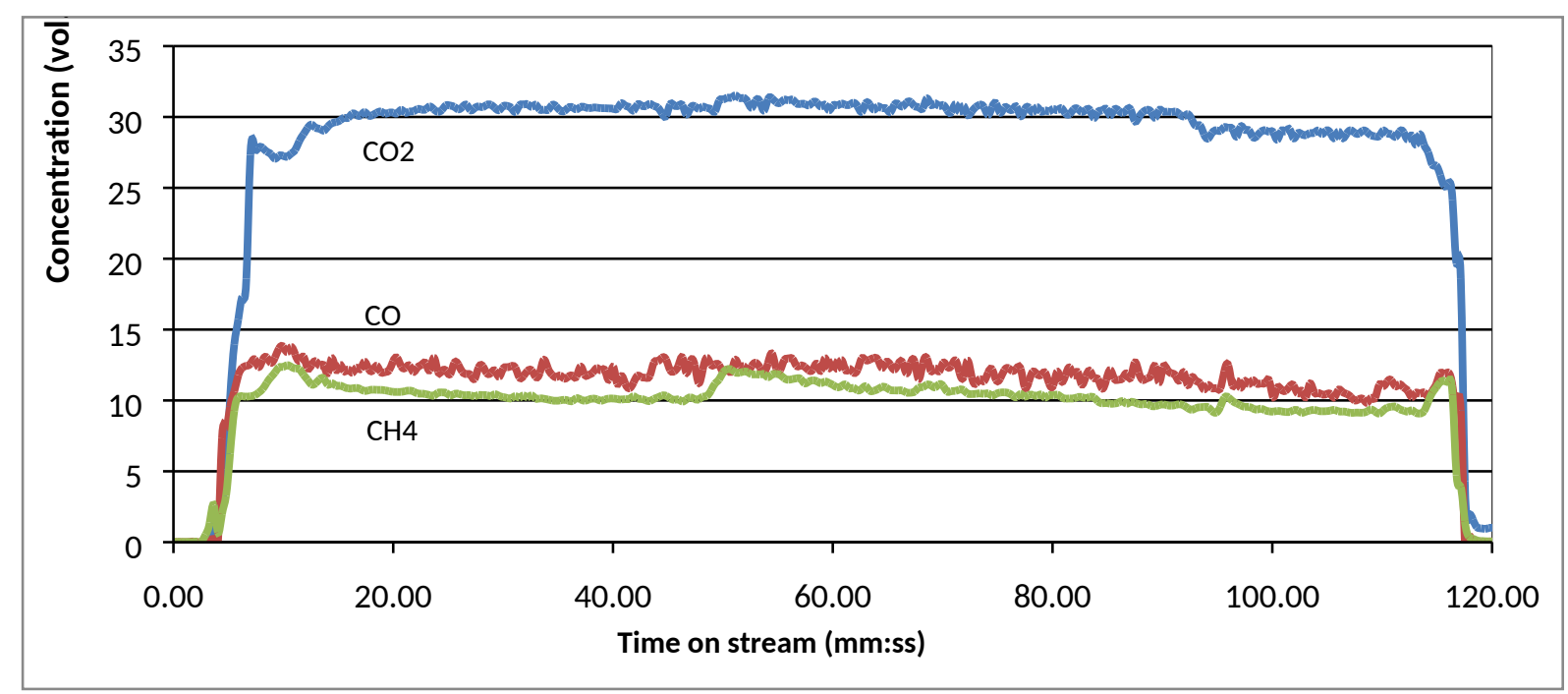

Figure 15: Measured gas composition on first stage syngas methanation ( $8 \% \mathrm{Ni}^{\prime} / \mathrm{Al}_{2} \mathrm{O}_{3}$ catalyst, GHSV: 10,566 $\mathrm{h}^{-1}$, Inlet-Outlet temperatures: $360-493^{\circ} \mathrm{C}$ ). Values are normalised for diluent $\mathrm{N}_{2}$ content. 


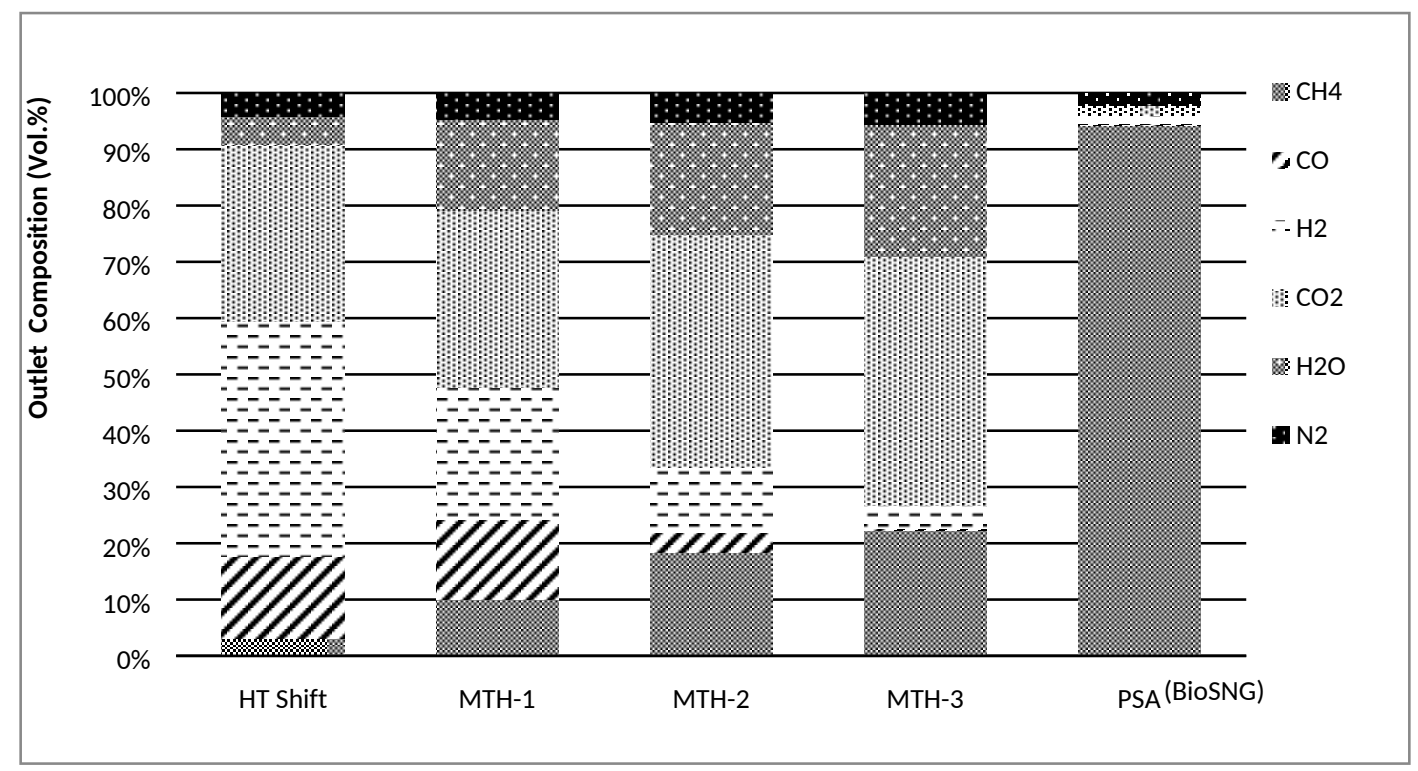

Figure 16: Average gas composition at main stages of the process (simulated). HT Shift $\left(\mathrm{Fe}_{2} \mathrm{O}_{3} / \mathrm{Al}_{2} \mathrm{O}_{3}-\right.$ outlet temperature: $353^{\circ} \mathrm{C}$ ), $\mathrm{MTH}-1$ (outlet temperature: $498^{\circ} \mathrm{C}$ ), $\mathrm{MTH}-2$ (outlet temperature: $412^{\circ} \mathrm{C}$ ), $\mathrm{MTH}-3$ (outlet temperature: $310^{\circ} \mathrm{C}$ ). 


\begin{tabular}{llcc}
\hline & Reaction name: & Reaction formula: & $\Delta \mathrm{H}_{\mathrm{R}}^{0}\left(\mathrm{~kJ} \mathrm{~mol}^{-1}\right)$ \\
\hline & Main reactions: & & \\
R1 & CO methanation & $\mathrm{CO}+3 \mathrm{H}_{2} \rightarrow \mathrm{CH}_{4}+\mathrm{H}_{2} \mathrm{O}$ & -206.1 \\
R2 & Water gas shift & $\mathrm{CO}+\mathrm{H}_{2} \mathrm{O} \rightarrow \mathrm{H}_{2}+\mathrm{CO}_{2}$ & -41.2 \\
& & & \\
& Secondary reactions: & $\mathrm{CO}_{2}+4 \mathrm{H}_{2} \rightarrow \mathrm{CH}_{4}+2 \mathrm{H}_{2} \mathrm{O}$ & -164.9 \\
R3 & Sabatier reaction & $\mathrm{CH}_{4}+\mathrm{H}_{2} \mathrm{O} \rightarrow \mathrm{CO}+3 \mathrm{H}_{2}$ & +206.1 \\
R4 & Steam reforming & $\mathrm{H}_{2}+\mathrm{CO}_{2} \rightarrow \mathrm{CO}+\mathrm{H}_{2} \mathrm{O}$ & +41.2 \\
R5 & Reverse water gas shift & $\mathrm{CH}_{4} \leftrightarrow \mathrm{C}+2 \mathrm{H}_{2}$ & +74.8 \\
R6 & Methane cracking & $2 \mathrm{CO}_{2} \leftrightarrow \mathrm{C}+\mathrm{CO}_{2}$ & -172.4 \\
R7 & Boudouard & $\mathrm{C}_{n} \mathrm{H}_{2 n} \leftrightarrow n \mathrm{C}+n \mathrm{H}_{2}$ & - \\
R8 & HC decomposition & & - \\
R9 & Hydrogenation & $n C O+(2 n+1) \mathrm{H}_{2} \leftrightarrow \mathrm{C}_{n} \mathrm{H}_{2 n+2}+\mathrm{nH}_{2} \mathrm{O}$ & \\
& & & \\
\hline
\end{tabular}

Table 1: Main reactions involved in the methanation of syngas 


\begin{tabular}{|l|l|l|}
\cline { 2 - 3 } \multicolumn{1}{c|}{} & Methanation Catalyst & Inert \\
\hline Volume & $25 \mathrm{ml}(50 \%$ diluted $)$ & $420 \mathrm{ml}$ \\
\hline Size $($ sieve $)$ & $0.15-0.8 \mathrm{~mm}$ & $1.5-2.0 \mathrm{~mm}$ sphere \\
\hline Bed voidage & 0.46 & 0.50 \\
\hline Composition & $8 \% \mathrm{Ni}-\mathrm{Al}_{2} \mathrm{O}_{3}$ & $\mathrm{Al}_{2} \mathrm{O}_{3}$ \\
\hline Surface area & $160 \mathrm{~m}^{2} \mathrm{~g}^{-1}$ & $2 \mathrm{~m}^{2} \mathrm{~g}^{-1}$ \\
\hline Particle density & $3.95 \mathrm{~g} \mathrm{~cm}^{-3}$ & $3.86 \mathrm{~g} \mathrm{~cm}^{-3}$ \\
\hline
\end{tabular}

Table 2: Catalyst bed dimension and composition (Catal International Itd) 


\begin{tabular}{|l|c|c|c|c|c|c|c|c|}
\cline { 2 - 9 } \multicolumn{1}{c|}{} & $\begin{array}{c}\mathbf{y C O} \\
{[\% \text { vol] }}\end{array}$ & $\begin{array}{c}\mathbf{y H}_{2} \\
{[\% \text { vol] }}\end{array}$ & $\begin{array}{c}\mathbf{y C O}_{2} \\
{[\% \text { \%ol] }}\end{array}$ & $\begin{array}{c}\mathbf{y N}_{2} \\
{[\% \text { vol] }}\end{array}$ & $\begin{array}{c}\text { GHSV } \\
{\left[\mathbf{h}^{-1}\right]}\end{array}$ & $\begin{array}{c}\text { Pressure } \\
{[\text { bar] }}\end{array}$ & $\begin{array}{c}\mathbf{H}_{2} / \mathbf{C O} \\
\text { molar }\end{array}$ & $\begin{array}{c}\text { Temperature } \\
\left.\text { range [ }{ }^{\circ} \mathbf{C}\right]\end{array}$ \\
\hline RUN 1 & 1.1 & 25.8 & 0.0 & 73.1 & 17,860 & 1 & 23.4 & $320-500$ \\
\hline RUN 2 & 2.3 & 25.7 & 0.0 & 72.0 & 17,935 & 1 & 11.2 & $335-516$ \\
\hline RUN 3 & 2.2 & 25.3 & 0.0 & 72.5 & 17,780 & 1 & 11.5 & $330-520$ \\
\hline RUN 4 & 3.3 & 25.4 & 0.0 & 71.3 & 17,888 & 1 & 7.6 & $320-506$ \\
\hline RUN 5 & 5.1 & 24.9 & 0.0 & 70.0 & 18,010 & 1 & 4.8 & $336-498$ \\
\hline RUN 6 & 6.1 & 24.8 & 0.0 & 69.1 & $\begin{array}{l}8,500- \\
19,840\end{array}$ & 1 & 4.1 & $335-478$ \\
\hline RUN 7 & 6.1 & 24.1 & 0.0 & 69.8 & 19,625 & 1 & 4.0 & $332-480$ \\
\hline RUN 8 & 6.0 & 36.2 & 0.0 & 57.8 & 18,750 & 1 & 6.0 & $325-540$ \\
\hline RUN 9 & 6.2 & 45.1 & 0.0 & 48.7 & 19,534 & 1 & 7.2 & $325-545$ \\
\hline RUN 10 & 6.2 & 72 & 0.0 & 21.8 & 18,566 & 1 & 11.6 & $325-555$ \\
\hline RUN 11 & 5.8 & 24.6 & 6.0 & 63.6 & $8,500-$ & 1 & 4.2 & $340-455$ \\
\hline RUN 12 & 5.6 & 24.5 & 6.1 & 62.9 & 19,000 & 1 & 4.4 & $342-455$ \\
\hline
\end{tabular}

Table 3: Experimental conditions for model development 


\begin{tabular}{|c|c|c|c|}
\hline \multicolumn{2}{|c|}{$\begin{array}{c}\text { Sheaf of lines equation } \\
\text { (with pCO, pH }=[\text { bar }]: T=[C])\end{array}$} & $(9)$ \\
\hline CO (alpha) & alpha $=\left[1.38 \mathrm{e}^{-3}+1.07 \mathrm{e}^{-6} *(760 * \mathrm{pH} 2-100)\right] * \mathrm{~T}+\left[-0.576-5.55 \mathrm{e}^{-5} *(750 * \mathrm{pH} 2-100)\right]$ & $(10)$ \\
\hline $\mathrm{H}_{2}$ (beta) & beta $=\left[-1.59 \mathrm{e}^{-3}+1.85 \mathrm{e}^{-6} *(760 * \mathrm{pCO}-20)\right] * \mathrm{~T}+\left[1.117+1.82 \mathrm{e}^{-3} *(750 * \mathrm{pCO}-20)\right]$ & $(10)$ \\
\hline
\end{tabular}

Table 4: Empirical kinetics order equations for $\mathrm{CO}$ methanation (derived from Figure 6). Range of temperature: $310-580^{\circ} \mathrm{C}$, range of partial pressures: $\mathrm{P}_{\mathrm{CO}}=0.025-0.22$ bar, $\mathrm{P}_{\mathrm{H} 2}=0.132-0.52$ bar 


\begin{tabular}{|c|c|c|c|c|c|c|c|}
\hline \multicolumn{2}{|r|}{ Reaction name } & \multirow{2}{*}{$\begin{array}{c}\begin{array}{c}\text { Activation } \\
\text { energy }\end{array} \\
\text { Ea }\left[\mathrm{kJ} \mathrm{mol}^{-1}\right]\end{array}$} & \multirow{2}{*}{$\begin{array}{c}\begin{array}{c}\text { Pre- } \\
\text { exponential } \\
\text { factor }\end{array} \\
\text { A } \\
\end{array}$} & \multicolumn{4}{|c|}{ Reaction order } \\
\hline & & & & $\mathrm{H}_{2}$ & $\mathrm{CO}$ & $\mathrm{CO}_{2}$ & $\mathrm{CH}_{4}$ \\
\hline R1 & $r_{C H 4}=A * e^{\left(-\frac{E a}{R T}\right)} * p_{H 2}^{a l p h a} * p_{C O}^{\text {beta }}$ & 95.8 & $3.36 \mathrm{E}+04^{(*)}$ & Eq.9 & Eq.10 & - & - \\
\hline R2 & $r_{W G S}=A * e^{\left(-\frac{E a}{R T}\right)} * p_{H 2}^{a} * p_{C O}^{b}$ & 57.9 & $4.41 \mathrm{E}+01$ & -0.2 & 0.57 & - & - \\
\hline R4 & $r_{S M R}=A * e^{\left(-\frac{E a}{R T}\right)} * p_{C H 4}$ & 193.5 & $1.55 \mathrm{E}+09$ & - & - & - & 0.92 \\
\hline R5 & $r_{r W G S}=A * e^{\left(-\frac{E a}{R T}\right)} * p_{C O 2}$ & 165.6 & $2.27 \mathrm{E}+05$ & - & - & 1 & - \\
\hline
\end{tabular}

Table 5: Reactions network model. ${ }^{*}$ Calculated for an average reaction order $n=0.45$ 


\begin{tabular}{|c|c|c|c|c|}
\hline \multirow{13}{*}{$\begin{array}{l}\text { Xu \& } \\
\text { Froment } \\
(1989)\end{array}$} & & \multicolumn{2}{|c|}{ Model parameters: } & \multirow{3}{*}{$\begin{array}{l}\text { Units: } \\
\text { mol bar }{ }^{0.5} \mathrm{~g}^{-1} \mathrm{~h}^{-1} \\
\mathrm{~kJ} \mathrm{~mol}^{-1}\end{array}$} \\
\hline & $k_{S M R}\left(P_{C O} P_{H 2}^{3}\right.$ & $k_{S M R}^{0}$ & $1.59 \times 10^{17}$ & \\
\hline & 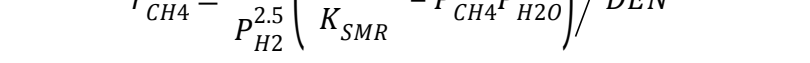 & $E_{S M R}$ & 248 & \\
\hline & & $k_{W G S}^{0}$ & $7.83 \times 10^{6}$ & mol bar $0.5 \mathrm{~g}^{-1} \mathrm{~h}^{-1}$ \\
\hline & & $E_{W G S}$ & 62 & $\mathrm{~kJ} \mathrm{~mol}^{-1}$ \\
\hline & $k_{W G S}\left(P_{\mathrm{CO} 2} P_{H 2}\right)$ & $K_{C O}^{0}$ & $8.23 \times 10^{-5}$ & bar \\
\hline & $r_{W G S}=\overline{P_{H 2}}\left(P_{C O} P_{H 2 O}-\overline{K_{W G S}}\right) / D E N^{2}$ & $\Delta H_{C O}$ & -70.65 & $\mathrm{~kJ} \mathrm{~mol}^{-1}$ \\
\hline & & $K_{H 2}^{0}$ & $6.12 \times 10^{-9}$ & bar \\
\hline & & $\Delta H_{H 2}$ & -82.90 & $\mathrm{~kJ} \mathrm{~mol}^{-1}$ \\
\hline & $+K_{H 2} P_{H 2}+K_{C H 4} P_{C H 4}+K_{H 2 O} P_{H 2 O} / P_{H 2}$ & $K_{\mathrm{CH} 4}^{0}$ & $6.65 \times 10^{-4}$ & bar \\
\hline & $v_{0} \quad\left(-E_{i}\right)$ & $\Delta H_{C H 4}$ & -32.28 & $\mathrm{~kJ} \mathrm{~mol}^{-1}$ \\
\hline & $\kappa_{i}=\kappa_{i} \exp (\overline{R T})$ & $K_{H 2 O}^{0}$ & $1.77 \times 10^{5}$ & bar \\
\hline & $K_{i}=K_{i}^{0} \exp \left(\frac{-\Delta H}{R T}\right) \quad i=H_{2}, \mathrm{CO} \mathrm{CH}_{4}, \mathrm{H}_{2} \mathrm{O}$ & $\Delta H_{H 2 O}$ & 88.68 & $\mathrm{~kJ} \mathrm{~mol}^{-1}$ \\
\hline Van & $Z_{1} P_{C O}^{0.5}$ & & & \\
\hline$(1982)$ & $r_{\mathrm{CH} 4}=\overline{\left(1+Z_{2}\left(P_{C O} / P_{H 2}\right)^{0.5}\right)^{2}}$ & Model & ameters: & Units: \\
\hline & $\quad\left(\Delta S^{0}, \quad-\Delta H\right.$ & $k T / h$ & 0.01 & - \\
\hline & $Z_{1}=\frac{k T}{h} \exp \left(\frac{\Delta S_{z 1}}{R}\right) \exp \left(\frac{-\Delta H_{z 1}}{R T}\right)$ & $\Delta S_{z 1}^{0}$ & -190.4 & $\mathrm{~J} \mathrm{~K}^{-1} \mathrm{~mol}^{-1}$ \\
\hline & $\begin{array}{lllllll} & R I & R\end{array}$ & $\Delta S_{z 2}^{0}$ & -44.5 & $\mathrm{~J} \mathrm{~K}^{-1} \mathrm{~mol}$ \\
\hline & $\left(\Delta S_{z 2}^{0}\right) \quad\left(-\Delta H_{z 2}\right)$ & $\Delta H_{z 1}$ & 35.2 & $\mathrm{~kJ} \mathrm{~mol}^{-1}$ \\
\hline & $Z_{2}=\exp (\bar{R}) \exp (\overline{R T})$ & $\Delta H_{z 2}$ & -33.0 & $\mathrm{~kJ} \mathrm{~mol}^{-1}$ \\
\hline
\end{tabular}

Table 6: Kinetic rate models on low-Nickel catalysts as developed by Xu \& Froment [35] and Van Meerten [39]. 


\begin{tabular}{|c|c|}
\hline & RDF (as received) \\
\hline \multicolumn{2}{|l|}{ Description: } \\
\hline $\mathrm{O}_{2} /$ fuel ratio $(\mathrm{w} / \mathrm{w})$ & 0.51 \\
\hline \multicolumn{2}{|l|}{ Proximate analysis, $\%(w / w)$} \\
\hline Fixed carbon & 6.4 \\
\hline Volatile matter & 59.6 \\
\hline Ash & 19.1 \\
\hline Moisture & 14.9 \\
\hline \multicolumn{2}{|l|}{ Ultimate analysis, \% (w/w) } \\
\hline $\mathrm{C}$ & 41.0 \\
\hline $\mathrm{H}$ & 5.7 \\
\hline $\mathrm{O}$ & 17.5 \\
\hline $\mathrm{N}$ & 1.2 \\
\hline$S$ & 0.2 \\
\hline $\mathrm{Cl}$ & 0.4 \\
\hline GCV, MJ kg-1 (dry basis) & 22.1 \\
\hline
\end{tabular}

Table 7: RDF proximate and ultimate analysis, and overall oxygen-fuel ratio used in the gasification system 


\begin{tabular}{|c|c|c|c|}
\hline \multirow{2}{*}{\multicolumn{2}{|c|}{ Quality Parameter: }} & \multicolumn{2}{|c|}{ Characterisation of cleaned syngas } \\
\hline & & From storage & Post-HT shift \\
\hline \multicolumn{4}{|c|}{ Composition: } \\
\hline $\mathrm{H}_{2}$ & vol.\% & 35.77 & 41.79 \\
\hline $\mathrm{CO}$ & vol.\% & 33.20 & 16.57 \\
\hline $\mathrm{CO}_{2}$ & vol.\% & 23.54 & 31.47 \\
\hline $\mathrm{CH}_{4}$ & vol.\% & 1.67 & 1.09 \\
\hline $\mathrm{H}_{2} \mathrm{O}$ & vol.\% & 0.89 & 4.96 \\
\hline Other & vol.\% & 4.90 & 4.12 \\
\hline TOTAL & vol.\% & 100.00 & 100.00 \\
\hline \multicolumn{4}{|c|}{ Trace contaminants } \\
\hline $\mathrm{H}_{2} \mathrm{~S}+\mathrm{COS}$ & ppmv & $<50$ & - \\
\hline Organic sulphur & ppbv & $<30$ & - \\
\hline Tars (+C6) & $\mu \mathrm{g} \mathrm{m}^{-3}$ & $<18$ & n.a. \\
\hline Acetylene & ppmv & $<40$ & n.a. \\
\hline \multicolumn{4}{|c|}{ Energy Analysis } \\
\hline $\mathrm{NCV}$ & $\mathrm{MJ} \mathrm{kg}^{-1}$ & 8.75 & 7.28 \\
\hline
\end{tabular}

Table 8: Gas composition before methanation in the Swindon pilot plant $\left(\sim 12.5 \mathrm{Nm}^{3} \mathrm{~h}^{-1}\right)$ 


\begin{tabular}{l|l|l}
\hline \multicolumn{3}{c}{ MTH -1 } \\
\hline Pressure & bar & 1.1 \\
Inlet temperature & ${ }^{\circ} \mathrm{C}$ & 330 \\
Outlet temperature & ${ }^{\circ} \mathrm{C}$ & $490-525$ \\
$\mathrm{~N}_{2}$ dilution & $\%$ & $70.2-9.7$ \\
GHSV & $\mathrm{h}^{-1}$ & $40000-10600$ \\
\hline Bed inventory & $\mathrm{mm}$ & 3.4 \\
\hline Particle size & vol.\% & 50 \\
Inert dilution &
\end{tabular}

Table 9: Operating parameters of the first methanation reactor in the pilot plant 


\begin{tabular}{|c|c|c|c|c|}
\hline \multirow{2}{*}{\multicolumn{2}{|c|}{ Quality Parameter: }} & \multicolumn{3}{|c|}{ First stage methanation $(8 \% \mathrm{Ni})$} \\
\hline & & $\begin{array}{c}\text { Model } \\
\text { (adiabatic) }\end{array}$ & $\begin{array}{c}\text { Pilot plant* } \\
\text { (2h average) }\end{array}$ & Error (\%) \\
\hline \multicolumn{2}{|c|}{ Outlet temperature $\left({ }^{\circ} \mathrm{C}\right)$} & 542 & 498 & \\
\hline \multicolumn{5}{|c|}{ Composition: } \\
\hline $\mathrm{H}_{2}$ & vol.\% & 23.53 & $(21.1)^{\#}$ & $10 \%$ \\
\hline $\mathrm{CO}$ & vol.\% & 14.18 & 12.82 & $10 \%$ \\
\hline $\mathrm{CO}_{2}$ & vol.\% & 31.35 & 29.8 & $5 \%$ \\
\hline $\mathrm{CH}_{4}$ & vol. $\%$ & 9.98 & 11.1 & $-11 \%$ \\
\hline $\mathrm{H}_{2} \mathrm{O}$ & vol.\% & 16.3 & 19.5 & $-20 \%$ \\
\hline $\mathrm{N}_{2}$ (from syngas) & vol.\% & 4.66 & $(5.68)^{\#}$ & $-22 \%$ \\
\hline TOTAL & vol.\% & 100.00 & 100.00 & \\
\hline \multicolumn{5}{|c|}{ Energy Analysis } \\
\hline $\mathrm{NCV}$ & $\mathrm{MJ} \mathrm{kg}^{-1}$ & 7.05 & 7.34 & \\
\hline
\end{tabular}

* values normalised for nitrogen dilution, ${ }^{\#}$ calculated

Table 10: Gas composition after methanation in the first reactor of the Swindon pilot plant: model and experimental data. 